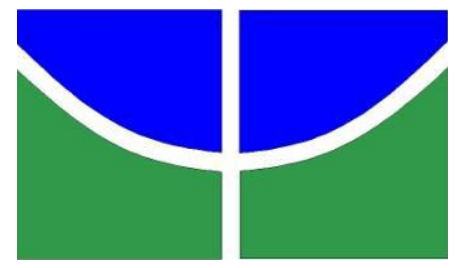

UNIVERSIDADE DE BRASÍLIA INSTITUTO DE CIÊNCIAS BIOLÓGICAS

DEPARTAMENTO DE BOTÂNICA

PROGRAMA DE PÓS-GRADUAÇÃO EM BOTÂNICA

JÉSSICA MAURA CUNHA SANTANA

ANÁLISE ESTRUTURAL E MICROMORFOLÓGICA DA LÂMINA FOLIAR DE POPULAÇÕES DE Guadua Kunth (POACEAE: BAMBUSOIDEAE:

GUADUINAE) OCORRENTES NO BRASIL

Brasília

Janeiro de 2017 
JÉSSICA MAURA CUNHA SANTANA

ANÁLISE ESTRUTURAL E MICROMORFOLÓGICA DA LÂMINA FOLIAR DE POPULAÇÕES DE Guadua Kunth (POACEAE: BAMBUSOIDEAE: GUADUINAE) OCORRENTES NO BRASIL

Dissertação apresentada como requisito à obtenção do grau de Mestre em Botânica. Programa de Pós-Graduação em Botânica, Departamento de Botânica, Instituto de Ciências Biológicas, Universidade de Brasília.

Orientadora: Prof ${ }^{a}$. Drª . Dalva Graciano-Ribeiro 
JÉSSICA MAURA CUNHA SANTANA

\section{ANÁLISE ESTRUTURAL E MICROMORFOLÓGICA DA LÂMINA FOLIAR DE POPULAÇÕES DE Guadua Kunth (POACEAE: BAMBUSOIDEAE: GUADUINAE) OCORRENTES NO BRASIL}

Esta Dissertação foi julgada adequada para obtenção do Título de Mestre em Botânica, e aprovada em sua forma final pelo programa de Pós-Graduação em Botânica da Universidade de Brasília.

Aprovado em 26 de Janeiro de 2017

BANCA EXAMINADORA

Prof a. Drª. Dalva Graciano Ribeiro (Orientadora)

Prof $^{a}$. Dr ${ }^{\mathrm{a}}$. Silvia Dias da Costa Fernandes (Membro titular)

Prof. Dr. Marcos José da Silva (Membro titular)

Prof. Dr. Thomas C. Rhys Williams (Membro suplente) 
A meus pais João Vicente da Cunha e Maria de Lourdes Mariano Cunha que nunca mediram esforços para que eu sempre pudesse alcançar meus objetivos, e por todos os ensinamentos para encarar a vida. 


\section{AGRADECIMENTOS}

A Deus por estar sempre presente cuidando de mim e de minha família. À Profa. Dalva Graciano Ribeiro, por ter acreditado em mim desde o nosso primeiro encontro e aceitado me orientar mesmo sem me conhecer muito bem. Por todos os ensinamentos, tanto profissionais quanto pessoais transmitidos, pela compreensão, paciência (essa ela teve muita rs!), conversas construtivas, preocupação, apoio e amizade. Muito obrigada! À Universidade de Brasília e ao Programa de Pós-graduação em Botânica pela oportunidade do curso; à Coordenação de Aperfeiçoamento de Pessoal de Nível Superior - CAPES, pela bolsa concedida. À Universidade Federal de Goiás, em especial ao Programa de Pós-Graduação em Biodiversidade Vegetal, por me receber como "aluna" durante esses dois longos anos de pesquisa, e por disponibilizar o carro para todas as coletas. Á Rede Bambu Goiás, pelo apoio financeiro na realização das coletas. Aos meus pais, pelo amor incondicional, confiança, incentivo e principalmente apoio em todas as etapas de minha vida. Obrigado por sempre estarem presentes e dispostos a ajudar no que fosse preciso. Ao meu esposo Erinaldo Júnior pelo amor, paciência, apoio e perseverança, pelas palavras de conforto e pelo ombro todas as vezes que me senti perdida. Aos meus irmãos: Jeorge André da Cunha, Lisandra Carolina da C. de Oliveira, e Laise Cristiane da C. Bassani pela constante preocupação, cumplicidade, apoio e confiança em todos os momentos e por sempre acreditarem que eu seria capaz. Aos meus cunhados: Eriton Carneiro de Oliveira, André Bassani Correia, Ednaldo Gomes Santana, Karla Cristina Santana e Eliomaria Gomes Santana pelas palavras de apoio, e por sempre me incentivarem a seguir firme em meus propósitos. Aos meus sobrinhos: Enzo, Melissa, Maurício e João Miguel, mesmo sendo tão pequenos me proporcionaram tantas alegrias nos poucos momentos em que pude visitá-los (a titia Keka ama vocês). Aos meus tios Filomena de Oliveira e Divino de Oliveira por serem meus maiores incentivadores aqui nessa cidade, por me receberem de braços abertos em sua casa, também por todas as orações e caronas. Aos professores do Departamento de Biodiversidade Vegetal da Universidade Federal de Goiás, pelo apoio e auxílio mesmo eu sendo aluna de outro programa. Aos amigos Diacis Alvarenga e Paulo R. Faria pelo apoio com as coletas, e por toda a 
diversão proporcionada durante as mesmas. À Silvia D. C. Fernandes, obrigada pelo apoio, ensinamentos, ajuda com a microscopia eletrônica e por sempre contribuir com meu trabalho. Ao Bruno pelo gigantesco apoio com as análises estatísticas, conselhos, amizade, e por sempre estar disposto a me ajudar. Aos meus amigos da UFG Priscila, Camila, Gustavo, Daniel, Jennifer, Juliane, Maria Eunice e Letícia pela cumplicidade e pelos momentos de diversão e descontração, em especial à Elifalete pelas conversas, desabafos e apoio. À Ana Fabrícia por me receber em sua casa nas idas à Brasília, pela amizade conversas, apoio e incentivo. À Jéssika P. Vieira e Marcos Schliewe pela amizade e principalmente apoio com minhas correrias burocráticas dentro da UnB. Ao Serviço Nacional de Aprendizagem Industrial (SENAI) da Vila Canaã pela oportunidade de trabalho nesse finalzinho de mestrado, em especial à minha coordenadora Adriana A. de Carvalho por sempre me liberar as vezes que precisei e por acreditar na minha competência como profissional. $\mathrm{E}$ a todos aqueles que estiveram direta ou indiretamente presente durante a execução deste trabalho. Peço desculpas se deixei alguém de fora, mas saibam que sou grata a todos. 
"Não fui eu que ordenei a você? Seja forte e corajoso! Não se apavore nem desanime, pois, o Senhor, o seu Deus, estará com você por onde você andar". 


\section{LISTA DE FIGURAS CAPÍTULO 01}

Figura 01: Superfície foliar das populações de Guadua estudadas evidenciando a face adaxial. a: $G$. cf magna; b: G. cf refracta; c: $G$. chacoensis; d: G. magna; e: G. paniculata; f: G. refracta; g: G. sp 01; h: G. sp 02; i: G. sp 03; j: G. virgata. cb: células buliformes; es: estômato; cs: célula silicificada. cl: célula longa; $\mathbf{m t}$ :

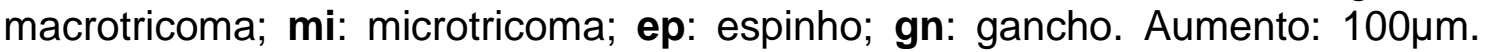

Fura 02: Figura 02: Superfície foliar das populações de Guadua estudadas evidenciando a face abaxial. a: $G$. cf magna; b: G. cf refracta; c: $G$. chacoensis; d: G. magna; e: G. paniculata; f: G. refracta; g: G. sp 01; h: G. sp 02; i: G. sp 03; j: G. virgata. zc: zona costal; zi: zona intercostal; cb: células buliformes; es: estômato; cs: célula silicificada. cl: célula longa; mt: macrotricoma; mi:

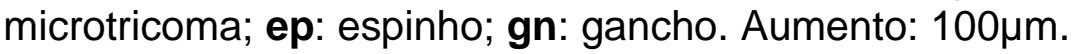
50

Figura 03. Epiderme adaxial das populações de Guadua Kunth estudadas, vistas em microscopia eletrônica de varredura, evidenciando a organização e disposição das células. a: $G$. aff. magna; b: $G$. aff. refracta; c: $G$. magna; d: $G$. paniculata; e: G. refracta; f: G. sp. 1; g: G. sp. 2; h: G. virgata . Zc: zona costal; Zi: zona intercostal; Cs: célula silicificada; Es: estômato; Ep: espinhos; Mi: microtricomas; Ma: macrotricomas; Ci: células invaginantes. Zc: zona costal; Zi: zona intercostal; $\mathrm{Cb}$ : células buliformes; Cs: célula silicificada; Es: estômato; Ep: espinhos; Mi: microtricomas; Ma: macrotricomas; Ci: células invaginantes; círculos demarcam os estômatos. círculos mostram os estômatos. Barra = $100 \mu \mathrm{m}$ 51

Figura 4: Epiderme abaxial das populações de Guadua Kunth estudadas, vistas em microscopia eletrônica de varredura, evidenciando a organização e disposição das células. a: $G$. aff. magna; b: $G$. aff. refracta; c: $G$. magna; d: $G$. paniculata; e: G. refracta; f: G. sp. 1; g: G. sp. 2; h: G. virgata . Zc: zona costal; Zi: zona intercostal; Cs: célula silicificada; Es: estômato; Ep: espinhos; Mi: microtricomas; Ma: macrotricomas; Ci: células invaginantes; círculos demarcam os estômatos. Barra $=100 \mu \mathrm{m}$. 52

Figura 5: Detalhes das estruturas celulares: papilas e células silicificadas. a: papilas simples; b: papilas bifurcadas; c: papilas ramificadas. d: célula silicificada de formato sela; e: célula silicificada de formato arredondado; $f$ : célula silicificada de formato halter; $g$ : célula silicificada de formato reniforme; $h$ : célula silicificada de formato nodular. Barra =

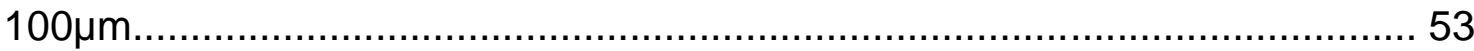

Figura 06: Detalhe dos estômatos observados nas populações de Guadua estudadas. a; b: superfície abaxial, estômatos rodeados por papilas; c: estômato abaxial com papilas ausentes em G. magna. d, e: superfície adaxial papilas formando câmara protetora; f: estômato adaxial com papilas ausentes em $\mathbf{G}$. aff. magna. Barra $=100 \mu \mathrm{m}$. $\mathbf{g}$, $\mathbf{h}$ : detalhe das células suberosas aos pares com as silicificadas; i: estômato de formato cúpula; j: estômato de formato triangular; $\mathrm{k}$ : estômato de formato paralelo. 
Figura 07: Figura 7. Detalhe dos tricomas vistos em microscopia eletrônica de varredura. a: macrotricoma longo com base envolta por papilas; b: macrotricoma curto, com a base recoberta por papilas; c, d: microtricomas bicelulares; e, f: espinhos com base dilatada e ápice reto; g, h: ganchos com base dilatada, envolta por papilas e ápice recurvado. Barra $=100 \mu \mathrm{m}$. 


\section{LISTA DE FIGURAS CAPÍTULO 02}

Figura 01: Secção transversal da lâmina foliar de espécies Guadua evidenciando o mesofilo homogêneo, formado por células invaginantes. A: $G$. cf magna; B: $G$. cf refracta; C: G. chacoensis; D: G. magna; E: G. paniculata; F: G. refracta; G: G. sp 01; H: G. sp 02; I: G. sp 03; J: G. virgata. cb: células buliformes; ct: cutícula; es: estômato; cf: célula fusoide; cec: células epidérmicas comuns; ci: células invaginantes; cs: célula silicificada; cv: cavidade subestomática; fv1: feixe vascular de $1^{\underline{a}}$ ordem; fv3: feixe vascular de $3^{\text {a }}$ ordem; pp: papilas. Barra $=100 \mu \mathrm{m}$. 71

Figura 02: Secção transversal da lâmina foliar de espécies Guadua evidenciando detalhes do bordo A. A: $G$. cf magna; B: $G$. cf refracta; C: $G$. chacoensis; D: $G$. magna; E: G. paniculata; F: G. refracta; G: G. sp 01; H: G. sp 02; I: G. sp 03; J: G. virgata. cb: células buliformes; ct: cutícula; es: estômato; fb: fbras; cf: célula fusoide; ci: células invaginantes; cs: célula silicificada; fv1: feixe vascular de 1 $^{\text {a }}$ ordem; fv3: feixe vascular de $3^{\text {a }}$ ordem; $\mathbf{~ c m}$ : cavidade de macrotricoma. Barra = $100 \mu \mathrm{m}$.

Figura 03: Secção transversal da lâmina foliar de espécies Guadua evidenciando detalhes do bordo B. A: $G$. cf magna; B: $G$. cf refracta; C: $G$. chacoensis; D: $G$. magna; E: G. paniculata; F: G. refracta; G: G. sp 01; H: G. sp 02; I: G. sp 03; J: G. virgata. $\mathbf{c b}$ : células buliformes; ct: cutícula; es: estômato; cf: célula fusoide; fb: fibras; ci: células invaginantes; cs: célula silicificada; fv1: feixe vascular de $1^{\text {a }}$ ordem; fv3: feixe vascular de $3^{\underline{a}}$ ordem; $\mathbf{c m}$ : cavidade de macrotricoma pp: papilas; tr: tricoma tector. Barra $=100 \mu \mathrm{m}$ 73

Figura 04: Secção transversal da lâmina foliar de espécies Guadua evidenciando detalhes da nervura central. A: $G$. cf magna; B: $G$. cf refracta; C: $G$. chacoensis; D: G. magna; E: G. paniculata; F: G. refracta; G: G. sp 01; H: G. sp 02; I: G. sp 03; J: G. virgata. cb: células buliformes; ct: cutícula; es: estômato; $\mathbf{c f :}$ célula fusoide; cec: células epidérmicas comuns; ci: células invaginantes; cs: célula silicificada; fv1: feixe vascular de $1^{\text {a }}$ ordem; fv2: feixe vascular de $2^{\underline{a}}$ ordem. Barra $=100 \mu \mathrm{m}$. 


\section{SUMÁRIO}

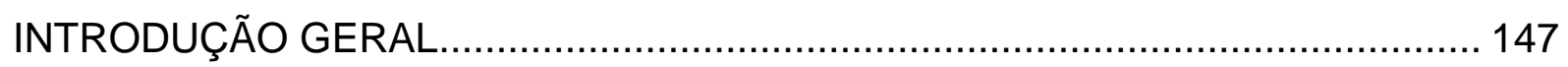

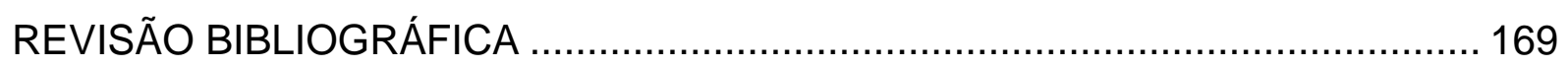

Poaceae

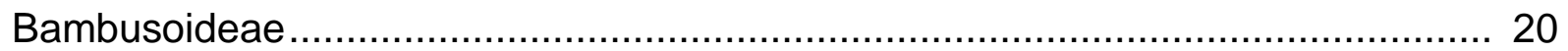

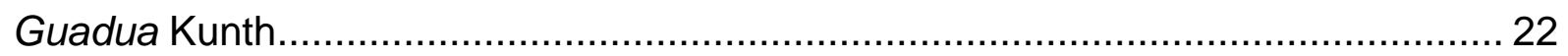

Anatomia foliar em Poaceae e Bambusoideae ……........................................ 2023

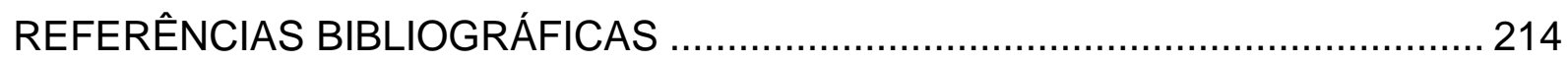

CAPÍTULO 01

Aspectos epidérmicos e micromorfológicos da superfície foliar de populações Guadua Kunth (POACEAE: BAMBUSODEAE: GUADUINAE) ocorrentes no Brasil ........ 2831

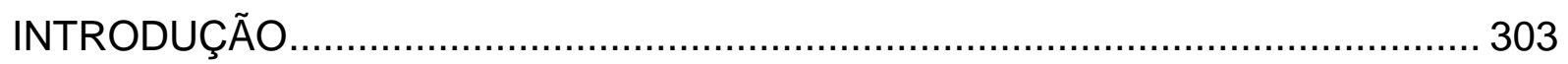

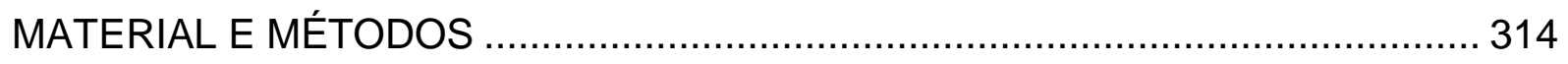

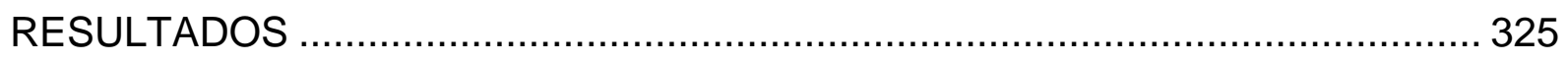

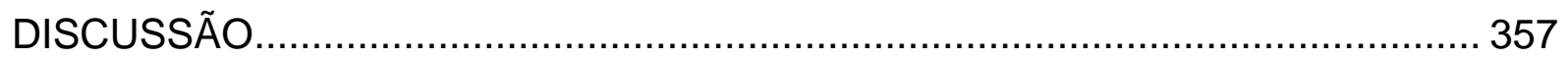

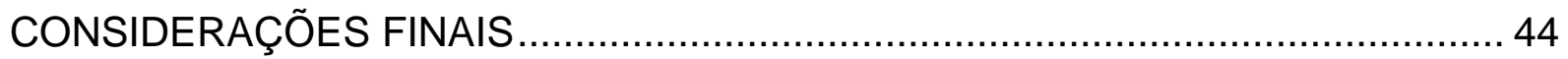

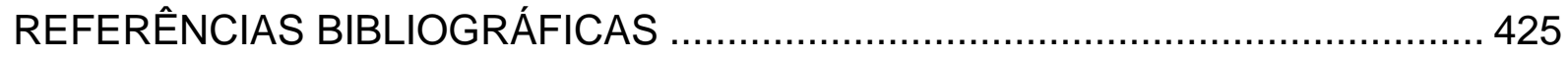

CAPÍTULO 02

Descrição, aspectos anatômicos em secção transversal, e descritores anatômicos para lâmina foliar de populações Guadua Kunth (POACEAE: BAMBUSODEAE:

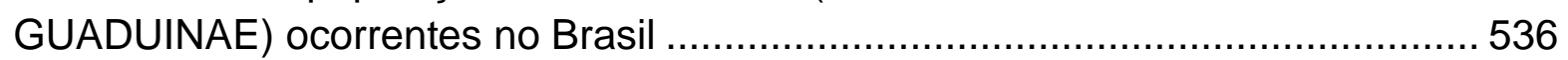

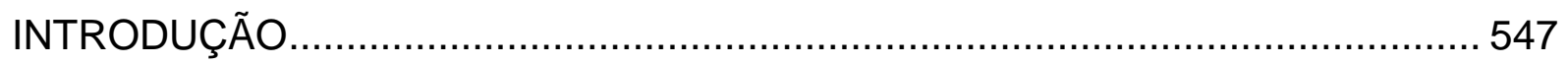

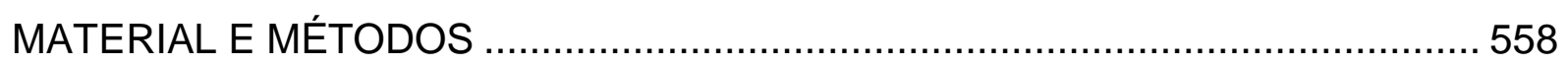

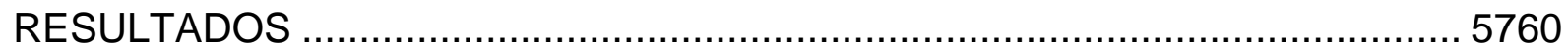

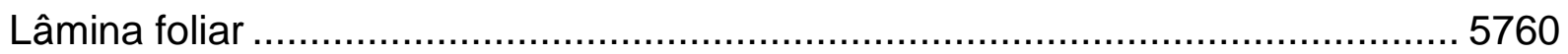

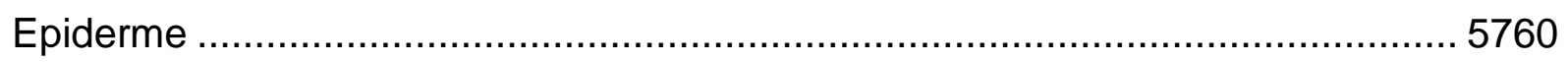

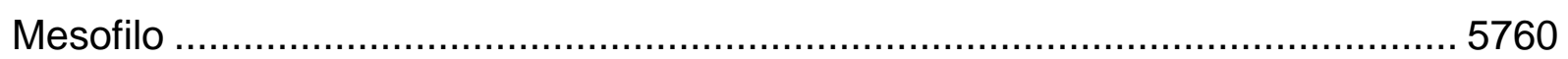

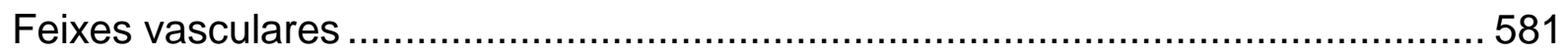

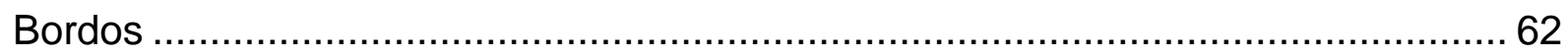

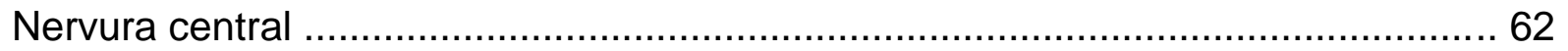

DISCUSSÃO

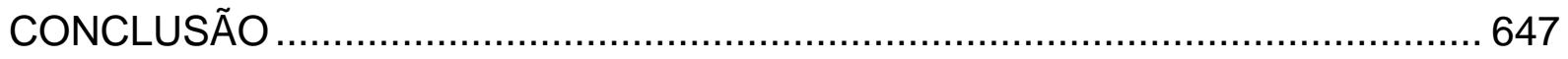

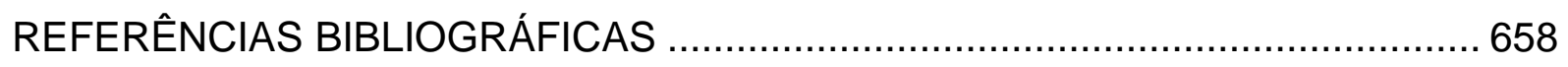




\section{RESUMO}

Bambusoideae compreende os "bambus verdadeiros" e suas espécies estão distribuídas em três tribos: Bambuseae, Olyreae e Arundinarieae. Bambuseae é citada como uma das tribos mais importantes, em função de suas aplicabilidades econômicas, ecológicas e culturais. No Brasil correm aproximadamente de 21 espécies de Guadua, e na região Centro Oeste são citadas cerca de nove espécies, todavia, pouco ainda se conhece sobre as populações de bambu ocorrentes nessa região. A anatomia foliar de bambus lignificados também é pouco conhecida, principalmente no que se refere a espécies coletadas no Brasil. Uma vez que a identificação tradicional baseia-se principalmente em caracteres morfológicos das flores, e nesses bambus as flores são raramente disponíveis, tal fato torna-se um fator limitante para estudos taxonômicos. Sendo assim, a morfoanatomia foliar representa uma importante ferramenta para auxiliar a caracterização e taxonomia do grupo. O presente trabalho buscou analisar os aspectos da anatomia foliar de 10 populações de Guadua Kunth a fim de caracterizá-las e contribuir com a delimitação do gênero. As Amostras foliares foram coletadas em diferentes localidades e armazenadas em etanol $70 \%+$ glicerina $50 \%$. Para secções paradérmicas porções da lâmina foliar foram submetidas à solução de Franklin adaptada; corados em solução de azul de metileno com ácido bórico. Para análises micromorfológicas os fragmentos de folhas seguiram metodologia usual para microscopia eletrônica de varredura, e para as secções transversais foram feitas secções à mão livre na região mediana das folhas coletadas, em seguida clarificadas com hipoclorito de sódio e submetidas à dupla coloração com azul de astra e safranina. Todas as lâminas permanentes foram montadas em lâmina e lamínula utilizando resina sintética. As descrições anatômicas seguiram de acordo com Metcalfe (1960), Ellis (1976; 1979), Graciano-Ribeiro et al. (2006) e Santos et al. (2010). A caracterização da lâmina foliar mostrou semelhanças entre as populações de Guadua aqui estudadas com outras populações de Guadua analisadas por outros autores. Além disso, as análises revelaram novidades sobre a organização anatômica das folhas das espécies atualmente aceitas para Guadua, tais como: ausência de microtricomas em G. magna e G. aff. magna, ausência de papilas $G$. magna, G. aff. magna e G. virgata, observados em secção paradérmica. Em secção transversal temos como principais diferenciais a ausência de células fusoides em $G$. chacoensis e $G$. paniculata e a presença de nervura central com sistema vascular simples apenas em $G$. paniculata. Tais características diferenciais observadas nas populações tanto neste estudo quanto no de outros autores, demonstram a importância de estudos com anatomia foliar para todas as espécies do gênero, uma vez que ainda são pouco estudadas com esse enfoque.

Palavras-chave: Anatomia foliar; Bambu; Microscopia Eletrônica de Varredura. 


\section{ABSTRACT:}

Bambusoideae comprises the "true bamboos" and their species are distributed in three tribes: Bambuseae, Olyreae and Arundinarieae. Bambuseae is cited as one of the most important tribes, due to its economic, ecological and cultural applicability. In Brazil, there are approximately 21 species of Guadua, and in the Central West region about nine species are cited, however, little is known about the bamboo populations occurring in this region. The leaf anatomy of lignified bamboos is also little known, especially in relation to species collected in Brazil. Since traditional identification is primarily based on morphological characters of flowers, and in these bamboos flowers are rarely available, this fact becomes a limiting factor for taxonomic studies. Thus, leaf morphoanatomy represents an important tool to aid the characterization and taxonomy of the group. The present study sought to analyze the aspects of the foliar anatomy of ten populations of Guadua Kunth in order to characterize them and contribute to the delimitation of the genus. The leaf samples were collected in different locations and stored in $70 \%$ ethanol $+50 \%$ glycerin. For paradermic sections portions of the leaf blade were submitted to the Franklin solution adapted; stained in methylene blue solution with boric acid. For micromorphological analyzes the leaf fragments followed the usual methodology for scanning electron microscopy, and for the cross sections were made freehand in the median region of the collected leaves, then clarified with sodium hypochlorite and submitted to double staining with astra blue and safranin. All the permanent blades were mounted on a blade and cover sheet using synthetic resin. The anatomical descriptions followed according to Metcalfe (1960), Ellis (1976; 1979), Graciano-Ribeiro et al. (2006) and Santos et al. (2010). The characterization of the leaf blade showed similarities between the populations of Guadua studied here with other populations of Guadua analyzed by other authors. In addition, the analyzes revealed novelties on the anatomical organization of the leaves of the species currently accepted for Guadua, such as: absence of microhairs in G. magna and G. aff. magna, absence of papillae G. magna, G. aff. magna and G. virgata, observed in a paradermic sections. In cross section we have as main differentials the absence of fusoid cells in $G$. chacoensis and G. paniculata, and the presence of central vein with simple vascular system only in G. paniculata. These differential characteristics observed in the populations both in this study and in other authors, demonstrate the importance of studies with leaf anatomy for all species of the genus, since they are still little studied with this approach.

Key-words: Leaf anatomy; Bamboo; Scanning Electron Microscopy. 


\section{INTRODUÇÃO GERAL}

Poaceae Barnhart pertence à ordem Poales, juntamente com Cyperaceae Juss., Eriocaulaceae Martynov, Bromeliaceae Juss. e outras 13 famílias (APG III, 2009). Está dividida em 12 subfamílias incluindo um clado de três linhagens (subfamílias Anomochlooideae Pilg. ex Potztal, Pharoideae L. G. Clark \& Judziewicz e Puelioideae L. G. Clark, M. Kobay., S. Mathews, Spangler \& E. A. Kellogg) e o clado formado por: Bambusoideae Luerss., Ehrhartoideae Jacq.-Fél. ex Caro e Pooideae Benth (BEP) e por Panicoideae A. Braun, Arundinoideae Burmeist, Chloridoideae Kunth ex Beilschm, Micrairoideae Pilg., Aristidoideae Caro e Danthonioideae H. P. Linder \& N. P. Barker (PACMAD) (GPWG II, 2012).

A subfamília Bambusoideae compreende os chamados "bambus verdadeiros" (JUDZIEWICZ et al., 1999), que constituem um grupo monofilético e suas espécies estão distribuídas em três tribos: Bambuseae Kunth ex Dumort. (bambus lignificados tropicais), Olyreae Kunth ex Spenn. (bambus herbáceos), e Arundinarieae Asch. \& Graebn. (bambus lignificados temperados) (JUDZIEWICZ et al., 1999; BREMER, 2002; SUNGKAEW et al., 2009). Diferentemente dos bambus herbáceos da tribo Olyreae, os bambus lignificados das tribos Arundinarieae e Bambuseae apresentam ramificação complexa, folhas do colmo, lígula externa nas folhas de ramo, flores bissexuadas e florescimento gregário monocárpico (na maioria das espécies) (JUDZIEWICZ et al., 1999; GPWG, 2001; FILGUEIRAS \& SANTOSGONÇALVES, 2004; BPG, 2012).

Bambuseae é citada como uma das tribos mais importantes, em função de suas aplicabilidades econômicas, ecológicas e culturais (LONDOÑO, 2004; SALGADO, 2014). Suas espécies estão distribuídas em sete subtribos das quais três são endêmicas do Novo Mundo: Chusqueinae Munro, Guaduinae Soderstr. \& R. P. Ellis e Arthrostylidiinae Munro (KELCHNER \& BPG, 2013).

Bambus estão distribuídos em praticamente todo o mundo, mas a maior riqueza de espécies é encontrada na Ásia-Pacífico e América do Sul (BYSTRIAKOVA et al., 2003). De acordo com Judziewicz et al. (1999), o Brasil é o país com a maior diversidade de espécies de bambu no Novo Mundo. Tal 
fato não é surpreendente se levarmos em consideração o imenso território e a diversidade de habitats que o país exibe.

Dentre os bambus neotropicais, Guadua Kunth. é um gênero de bambus lignificados importante na estruturação de ecossistemas e biodiversidade (FERREIRA, 2014). Os nichos criados pelas comunidades de Guadua permitem associações com várias espécies vegetais e animais. Apesar de estar tipicamente associados a formações florestais, existem espécies adaptadas a outros tipos de ambientes como o Cerrado, campo rupestre e campo de altitude (SODERSTROM, 1981).

No Brasil correm cerca de 21 espécies de Guadua, das quais 5 são endêmicas. Na região Centro Oeste são citadas cerca de 9 espécies: $G$. angustifolia Kunth, G. calderoniana Londoño \& Judz., G. chacoensis (Rojas) Londoño \& P.M. Peterson, G. maculosa (Hack) E.G. Camus, G. magna Londoño \& Filg, G. paniculata Munro, G. refracta Munro, G. tagoara (Ness) Kunth e G. virgata (Trin) Rupr. (SHIRASUNA, 2015).

A taxonomia de bambus, principalmente lignificados, é altamente controversa, algumas espécies e gêneros sofreram várias revisões com base em conjuntos alternativos de caracteres, enquanto os dados moleculares ainda fornecem pouca resolução e apoio para classificações morfológicas (GUO et al., 2002; PENG et al., 2008; SUNGKAEW et al., 2009; KELCHNER \& BPG, 2013; FISHER et al., 2014; ZHAO et al., 2015).

A anatomia foliar de bambus lignificados também é pouco conhecida, pois a identificação tradicional baseia-se principalmente em caracteres morfológicos das flores, e nesses bambus as flores são raramente disponíveis (JUDZIEWICZ et al., 1999; ALVES, 2007; ). A maior parte dos bambus lignificados possui floração gregária, com isso a obtenção de amostras que incluam as estruturas reprodutivas constitui um fator limitante para estudos taxonômicos (AZZINI et al., 1978). Nesse contexto, a morfoanatomia foliar representa uma importante ferramenta para auxiliar a caracterização e taxonomia do grupo (OLIVEIRA et al., 2008; GUERREIRO et al., 2013; LEANDRO et al., 2016) 
O presente trabalho buscou analisar os aspectos da anatomia foliar de espécies de Guadua Kunth vistas em secção transversal, a fim de caracterizar as espécies e contribuir com a delimitação do gênero.

\section{REVISÃO BIBLIOGRÁFICA}

\section{Poaceae}

Poaceae é representada por capins, bambus e cereais, considerada uma das principais famílias entre as angiospermas (JUDD et al., 2002; LONGHI-WAGNER, 2012; SORENG et al., 2015; SYLVESTER, 2016). Possui cerca de 700 gêneros e cerca de 11.000 espécies (GPWG, 2001). Filgueiras et al. (2016) citaram cerca de 1.486 espécies, distribuídas em 225 gêneros ocorrendo no Brasil.

Está representada por plantas conhecidas como gramíneas. É uma das famílias com maior variedade de hábitos no grupo das Angiospermas. Podem ser anuais ou perenes, apresentar lignificação ou não, geralmente são rizomatosas. Os colmos podem ser sólidos ou ocos, herbáceos ou lignificados, variam em tamanho e diâmetro, podendo ser eretos, ascendentes ou procumbentes. Os nós presentes nos colmos são cobertos por folhas quando jovens, e os entrenós na maioria das vezes são sólidos. As folhas são dísticas e alternas; apresentam bainha, lígula, podendo também ser pilosa em algumas espécies. A inflorescência é do tipo panícula com agrupamento de espiguetas (GPWG, 2001; JUDZIEWICZ \& CLARK, 2007).

Apresentam também distribuição cosmopolita e sua importância econômica é amplamente reconhecida, uma vez que pertencem a esta família grãos como Oryza sativa L. (arroz), Triticum aestivum L. (trigo), Zea mays L. (milho) e Saccharum officinarum L. (cana-de-açúcar), considerados alimentos básicos para as populações humanas (ARRIETA \& ORTIZ, 2010) e várias outras espécies com alta produção e potencial biocombustível (BYRT et al., 2011; ZHOU et al., 2013; TRUONG \& LE, 2014).Incluem também espécies forrageiras, como braquiária - Urochloa decumbens (Stapf) Webster e capim- 
colonião - Panicum maximum Jacq (BODDEY et al., 2004) fontes principais de alimentação para o gado. Além disso, diversos membros da família são dominantes ecológicos, e cobrem cerca de $20 \%$ da superfície terrestre, aspecto que se reflete em várias fitofisionomias (KELLOGG, 2001; CAPORAL \& EGGERS, 2005; WELKER \& LONGHI-WAGNER, 2007; CARDOSO et al., 2013; ROLIM et al., 2014).

É uma família representativa ao longo da floresta atlântica, sendo esta considerada como um grande centro de diversidade de bambus (SODERSTROM et al., 1988), cujas espécies são representantes da subfamília Bambusoideae (KELLOGG, 2001; GRECO, 2013).

\section{Bambusoideae}

A subfamília abrange 116 gêneros e 1.439 espécies, cerca de dois terços dessa diversidade ocorre nas zonas tropicais (BPG, 2012; YEASMIN et al., 2015). Apresenta distribuição ampla no planeta, ocorrem naturalmente em quase todos os continentes, exceto Europa e Antártida (KELCHNER \& BPG 2013); cerca de $62 \%$ das espécies são nativas do continente asiático, $34 \%$ das Américas e 4\% da África e da Oceania (HIDALGO LOPEZ 2003). Entretanto, acredita-se que a diversidade de bambus nativos do continente americano seja equivalente à da Ásia, já que muitas espécies ainda não foram descritas (CRUZ RíOS 2009). Também são popularmente conhecidos como o "ouro verde da floresta" devido às suas várias aplicações (GOYAL et al., 2014; PEREIRA \& BARATA, 2015; BALDUINO JUNIOR et al., 2016).

Além de sua ampla distribuição, os bambus apresentam grande diversidade morfológica, sua floração pode ocorrer em um ciclo de 28 a 32 anos (NELSON \& BIANCHINI, 2005) até cerca de 120 anos (AZZINI et al., 1978). O florescimento é de forma sincronizada dentro de cada população, após a floração, as espécies morrem, o que dificulta o estudo das características florais (LIN et al., 2003). Outras espécies têm ciclos mais curtos, 
cerca de 8 a 10 anos, porém, ainda muito longos (FRANKLIN, 2004) quando comparados a bambus herbáceos.

Constituem um grupo monofilético dentro de Poaceae e podem ser reconhecidos através de suas características morfológicas, anatômicas, citológicas, macromoleculares e ecológicas (BREMER, 2002; STEVENS, 2016). Os conjuntos de dados acima citados são empregados para classificar as espécies que compõem esse vasto grupo de plantas (FILGUEIRAS \& SANTOS-GONÇALVES, 2011).

É caracterizada pelas seguintes sinapomorfias: plantas perenes (raro anuais), hábito rizomatoso, ramificação simples ou complexa, folhas pseudopecioladas, mesofilo com células invaginantes assimétricas, associadas a células fusoides e células buliformes, microtricomas alongados com paredes delgadas (JUDZIEWICZ et al., 1999).

O Brasil é um dos países com a maior riqueza de bambus no mundo, e a maior da diversidade no hemisfério ocidental (SODERSTROM et al., 1988; CLARK, 1990; JUDZIEWICZ et al., 1999); Filgueiras \& Santos-Gonçalves (2004) citaram 34 gêneros e cerca de 232 espécies, mas novos táxons têm sido descritos, incluindo novos gêneros (FERREIRA et al., 2013a; VIANA et al., 2013a) e novas espécies (OLIVEIRA \& CLARK, 2009; SANTOS-GONÇALVES et al., 2011; 2012; CARVALHO et al., 2012; FERREIRA et al., 2013b; VIANA et al., 2013b; LIZARAZU et al., 2013; MOTA et al., 2014; FERREIRA et al., 2016).

As espécies de bambu mais utilizadas na América Latina são as do gênero Guadua e do gênero asiático Bambusa Burnett, embora outros gêneros também sejam utilizados. Sendo que o cultivo de bambus em escala comercial está limitado a algumas espécies nativas, juntamente com espécies introduzidas: Guadua angustifolia Kunth, Guadua amplexifolia J. Presl, Bambusa vulgaris Schrad. ex J.C. Wendl., Bambusa tuldoides Munro e Phyllostachys aurea Carrière ex Rivière \& C. Rivière (GHAVAMI \& MARINHO, 2005; SILVA, et al., 2011; BPG, 2012). 


\section{Guadua Kunth}

Contém aproximadamente 28 espécies, amplamente distribuídas nas Américas, possuem porte mediano a grande, colmos e ramos com espinhos recurvados que auxiliam a sua fixação em outras plantas (LONDOÑO \& PETERSON, 1992; YOUNG \& JUDD, 1992). A sua maior diversidade ocorre na região amazônica da Bolívia, Brasil, Colômbia, Equador, Peru e Venezuela (LONDOÑO, 2013).

Olivier et al. (2009) descreveram Guadua como um gênero de bambu neotropical presente na Amazônia muito antes do que qualquer atividade humana, descartando as teorias onde os estabelecimentos das florestas dominadas por bambus são atribuídos a causas antropogênicas.

Assim como outros bambus lignificados, Guadua possui florescimento monocárpico, ou seja, cada população individual apresenta um único evento com floração e frutificação maciças e sincrônicas (JANZEN, 1976; NADGAUDA et al., 1990). No sudoeste da Amazônia a longevidade das populações de Guadua é estimada entre 27 e 28 anos (CARVALHO et al., 2013).

Dentre os bambus neotropicais, Guadua caracteriza-se por colmos ocos que podem ser eretos arqueados no ápice ou escandentes, de porte médio a grande, cerca de $30 \mathrm{~m}$ de altura e 2 a $15 \mathrm{~cm}$ de diâmetro, podendo ser encontradas também espécies que possuem colmos sólidos. As folhas caulinares possuem formato triangular, sendo as margens da lâmina e da bainha são contínuas. O entrenó geralmente apresenta um sulco acima da inserção dos brotos dos ramos, estes por sua vez são espinescentes, com espinhos mais desenvolvidos na base do colmo. Os rizomas podem ser curtos ou longos. Apresentam ainda, uma banda de pelos brancos na região do nó (LONDOÑO \& SODERSTROM, 1987; JUDZIEWICZ \& LONDOÑO, 1991; LONDOÑO \& PETERSON, 1991; JUDZIEWICZ et al., 1999; LONDOÑO, 2001; GRISCOM \& ASHTON, 2003). 


\section{Anatomia foliar em Poaceae e Bambusoideae}

Caracteres anatômicos foliares vêm sendo incluídos para auxiliar na definição das subfamílias de Poaceae, que têm sido caracterizadas pela combinação de dados anatômicos, morfológicos (LONDOÑO, 2002; MONTIEL et al., 2006; PELEGRIN, 2008; OLIVEIRA et al., 2008; GUGLIERI et al., 2008; SOTO et al., 2009; SILVA et al., 2011) e por vezes moleculares (RUIZSANCHEZ et al., 2011; CHOKTHAWEEPANICH et al., 2014; SORENG et al., 2015). Os caracteres da anatomia foliar incluindo a epiderme, têm relevância nas categorias de gênero e espécie em Poaceae, mas têm sido principalmente utilizados para reforçar a divisão em subfamílias (SNOW, 1996).

Bambus diferem das outras gramíneas na anatomia da folha das seguintes maneiras: apresentam mesofilo não radiado, composto por células invaginantes e fusoides; mais que um feixe vascular na nervura central, e as células silicificadas estão orientadas verticalmente (SODERSTROM \& ELLIS, 1987). Estudos como os de Soderstrom \& Ellis (1987) e Ding \& Zhao (1994) mostram que há uma correlação significativa entre a anatomia das folhas de bambu e táxons diferentes. No caso dos bambus, a anatomia tem sido útil para, além de caracterizar, delimitar Bambusoideae de outras gramíneas e definir as tribos que a compõem, mas tem sido pouco utilizada para definir os grupos menores, como os gêneros e espécies (LONDOÑO, 2002).

Vários pesquisadores têm estudado a anatomia do colmo em espécies nativas de Guadua (RODRIGUEZ, 2002; 2003; LONDOÑO et al., 2002; LONDOÑO et al., 2003; MIRANDA, 2016), entretanto, estudos sobre a anatomia foliar de espécies de Guadua ainda são escassos, sobretudo com espécies coletadas no Brasil (GRACIANO-RIBERIO et. al., 2010, CUNHASANTANA, 2016). 


\section{REFERÊNCIAS BIBLIOGRÁFICAS}

ARRIETA, Y.H.; ORTIZ A. C. Listado Florístico y Aspectos Ecológicos de la Família Poceae. Journal of the Botanical Research Institute of Texas. V.4(2). 2010.

AZZINI, A; CIARAMELLO, D.; NAGAI, V. Propagação vegetativa do bambugigante. Bragantia online, vol.37, n.1, pp. 1-3. ISSN 1678-4499. 1978. Disponível em http://www.scielo.br/pdf/brag/v37n1/17.pdf. Acesso em 05 out 2016.

BALDUINO JUNIOR, A.L.; BALDUINO, T.Y.; DA CUNHA, F.A.B.; BRANDI, M.A. Energetic potential of bamboo culms for industrial and domestic use in Southern Brazil Potencial energético de colmos de bambu para uso industrial e doméstico na região sul do Brasil. Ciência Rural. v.46(11) pp. 1963-1968. 2016.

BAMBOO PHYLOGENY GROUP (BPG). An updated tribal and subtribal classification of the bamboos (Poaceae: Bambusoideae). In: The Journal of the American Bamboo Society. v.24(1). pp. 1-10. 2012.

BODDEY, R. M.; MACEDO, R.; TARRÉ, R. M. Nitrogen cycling in Brachiaria pastures: the key to understanding the process of pasture decline. Agriculture, Ecosystems and Environment. v.103. pp.389-403. 2004.

BREMER, K. Gondwanan Evolution of the Grass Alliance of Families (Poales). Society for the Study of Evolution. v.56(7). pp. 1374-1387. 2002.

BYRT, C.S.; GROF, C.P.L.; FURBANK, R. T. C4 plants as biofuel feedstocks: optimising biomass production and feedstock quality from a lignocellulosic perspective. Journal of Integrative Plant Biology v.53. pp. 120-135. 2011.

BYSTRIAKOVA, N.; KAPOS, V.; LYSENKO, I.; STAPLETON, C. Distribution and conservation status of forest bamboo biodiversity in the Asia-Pacific region. Biodiversity Conservation. v.12. pp. 1833-1841. 2003.

CAPORAL, F. J. M; EGGERS, L. Poaceae na área do Centro de Pesquisas e Conservação da Natureza Pró-Mata, São Francisco de Paula, Rio Grande do Sul, Brasil. Iheringia Série Botânica. v.6(2). pp.141-150. 2005.

CARVALHO, A. L.; NELSON, B.W.; BIANCHINI. M.C.; PLAGNOL, D.; KUPLICH, T.M.; DALY, D. C. Bamboo-Dominated Forests of the Southwest Amazon: Detection, Spatial Extent, Life Cycle Length and Flowering Waves. Amazonian Bamboo Forests. v.8. 2013.

CARVALHO, M. L.S.; DÓREA, M. C.; PIMENTA, K. M; OLIVEIRA, R. P. Piresia palmula: a new species of herbaceous bamboo (Poaceae: Olyreae) endemic to the Atlantic Rainforest, Southern Bahia, Brazil. Systematic Botany. v.37. pp. 134-138. 2012.

CHOKTHAWEEPANICH, H.; FISHER, A.E.; DRANSFIELD, S.; WIDJAJA, E.A.; WONG, K.M.; RATTAMANEE, C.; KELCHNER, S.; CLARK, L.G. Phylogeny 
and classification of the paleotropical woody Bamboos (Poaceae: Bambusoideae: Bambuseae) based on six plastid markers. Tese. lowa State University. 2014.

CUNHA-SANTANA, J.M.; FERNANDES, S.D.C.; GRACIANO-RIBEIRO, D. Morfoanatomia e Micromorfologia da lâmina foliar de Guadua Refracta Munro (POACEAE-BAMBUSOIDEAE): Bambu endêmico do Brasil. In: Anais, 67 Congresso Nacional de Botânica. Vitória, ES. 2016.

FERREIRA, E.J.L. O bambu é um desafio para a conservação e o manejo de florestas no sudoeste da Amazônia. Ciencia e Cultura online. v.66(3). pp.4651. 2014.

FERREIRA, F. M.; HOLLOWELL, V. C.; VAN DEN BERG, C.; OLIVEIRA, R. P. Parianella (Poaceae: Bambusoideae): morphological and biogeographical information reveals a new genus of herbaceous bamboos from Brazil. Phytotaxa. v.77. pp. 27-32. 2013a.

FERREIRA, F. M., DÓREA, M. C., LEITE, K. R. B.; OLIVEIRA, R. P. Eremitisa fimbriata and E. magnifica (Poaceae: Bambusoideae: Olyreae): two remarkable new species from Brazil and a first record of blue iridescence in bamboo leaves. Phytotaxa. v.84. pp. 31-45. 2013b.

FILGUEIRAS, T. S.; LONGHI-WAGNER, H. M.; VIANA, P. L.; ZANIN, A.; OLIVEIRA, R. C. DE; CANTO-DOROW, T. S.; RODRIGUES, R. S.; SANTOSGONÇALVES, A. P.; WELKER, C. A. D.; FERREIRA, F. M.; CARVALHO, M. L. S.; SILVA, A.S.; MOTA, A.C.; VALLS, J.F.M.; SHIRASUNA, R.T.; REIS, P.A.; DÓREA, M.C.; SILVA, C.; OLIVEIRA, R.P. Poaceae in Lista de Espécies da Flora do Brasil. Jardim Botânico do Rio de Janeiro, 2015. Disponível em: $<$ http://floradobrasil.jbrj.gov.br/jabot/floradobrasil/FB193>. Acesso em: 20 set 2016.

FILGUEIRAS T. S.; SANTOS-GONÇALVES, A. P. S. Bambus nativos no Brasil: oportunidades e desafios para seu conhecimento. Anais do I Seminário Nacional do Bambu. 2. ed. Brasília: CPAB, Universidade de Brasília. 196p. 2011.

FILGUEIRAS, T. S.; SANTOS-GONÇALVES, A. P. S. A Checklist of the Basal Grasses and Bamboos in Brazil (POACEAE). Bamboo Science and Culture: The Journal of the American Bamboo Society. v.18(1). pp. 7-18. 2004.

FISHER, A.E.; CLARK, L.G.; KELCHNER, S.A. Molecular phylogeny estimation of the bamboo genus Chusquea (Poaceae: Bambusoideae: Bambuseae) and description of two new bamboo subgenera. Systematic Botany. v.39(3), pp. 829-844. 2014

FRANKLIN, D. C. Synchrony and asynchrony: observations and hypotheses for the flowering wave in a long-lived semelparous bamboo. Journal of Biogeography. v.5(31). pp. 773-786. 2004.

GHAVAMI, K.; MARINHO, A. B. Propriedades físicas e mecânicas do colmo inteiro do bambu da espécie Guadua angustifolia. Revista Brasileira de Engenharia Agrícola e Ambiental. v.9(1). pp.107-114. 2005. 
GOYAL, A. K.; KAR, P.; SEM, A. Advancement of bamboo taxonomy in the era of molecular biology: a review. Biology of useful plants and microbes. pp. 197-208. 2014.

GPWG (Grass Phylogeny Working Group). New grass phylogeny resolves deep evolutionary relationships and discovers C4 origins. New Phytologist. v.193. pp. 304- 312. 2012.

GPWG, Phylogeny and subfamilial classification of the grasses (Poaceae). Annals of the Missouri Botanical Garden. v.88. pp. 373-457. 2001.

GRACIANO-RIBEIRO, D.; PAULUCIO, F.F.; RODRIGUES, T.S; FILGUEIRAS, T.S.; VERAS, D.S. Anatomia foliar de bambus (Poaceae: Bambusoideae) ocorrentes no Centro-Oeste. In: Anais/Resumos: 62 ${ }^{\mathbf{a}}$ Reunião Anual da SBPC - ISSN 2176-1221, 2010.

GRECO, T. M. Diversidade de Bambus (Poaceae: Bambusoideae) na ilha de Santa Catarina, Brasil. Dissertação. Universidade Federal de Santa Catarina. 2013.

GRISCOM, B.W. \& ASHTON, P.M.S. Bamboo control of forest succession: Guadua sarcocarpa in Southeastern Peru. Forest Ecology and Management. v.175. pp. 445-454. 2003.

GUERREIRO, C.; RÚGULO DE AGRASAR, Z.E.; RODRIGUEZ, M.F. A contribution to the identification of vegetative Andean woody bamboos in southernmost America using leaf anatomy. The Journal of the Torrey Botanical Society. 2013.

GUGLIERI, A.; LONGHI-WAGNER, H. M.; ZULOAGA, F. O. Anatomia foliar das espécies de Panicum L. subg. Panicum (Poaceae: Panicoideae: Paniceae) ocorrentes no Brasil. Iheringia Série Botânica. v.63. pp. 279-293. 2008.

JANZEN, D. H. Why Bamboos Wait so Long to Flower? Annual Review of Ecology and Systematics. v.7. pp.347-391. 1976.

JUDD, W. F.; KELLOGG, E. A; STEVENS, P. F.; DONOGHUE, M. J. Plant Systematics: a Phylogenetic Approach, Second Edition. Sinauer Associates, Massachusetts, Estados Unidos, 2002.

JUDZIEWICZ, E. J.; CLARK, L. G.; LONDOÑO, X. \& STERN, M. J. American bamboos. Washignton, D. C., Smithsonian Institution Press, 392 pp, 1999.

JUDZIEWICZ, E. J.; CLARK. L. G. Classification and biogeography of New World grasses: Anomochlooideae, Pharoideae, Ehrhartoideae, and Bambusoideae. Aliso: Journal of Systematic and Evolutionary Botany. v. 23. p. 303-314. 2007.

JUDZIEWICZ. J. E.; LONDOÑO, X. A New Species of Guadua, G. calderoniana (Poaceae: Bambuseae), with Notes on the Genus in Bahia, Brazil. Missouri Botanical Garden Press. Novon. v.1(1). pp. 27-32. 1991. 
KELCHNER, S.A.; BPG. Higher level phylogenetic relationships within the bamboos (Poaceae: Bambusoideae) based on five plastid markers. Molecular Phylogenetics and Evolution, v. 67, p. 404-413. 2013.

KELLOGG, E. A. Evolutionary History of the Grasses. American Society of Plant Physiologists. v.125. pp.1198-1205. 2001.

LEANDRO, T.D.; SHIRASUNA, R.T.; FILGUEIRAS, T.S.; SCATENA, V.L. The utility of Bambusoideae (Poaceae, Poales) leaf blade anatomy for identification and systematics. Brazilian Journal of Biology. 2016.

LIN, C. S.; LIN, C. C.; CHANG, W. C. In vitro flowering of Bambusae dulis and subsequent plantlet survival. Plant Cell Tissue and Organ Culture, 2003. In: http://link.springer.com/article/10.1023\%2FA\%3A1021281217589. Acesso em 29 nov. 2016.

LIZARAZU, M.A.; RÚGULO DE AGRASAR, Z.E.; VEGA, A.S. A New Species of Guadua (Poaceae, Bambusoideae, Bambuseae) and Synopsis of the Genus in Argentina and Neighboring Regions. Systematic Botany. v. 38. pp. 10621075, 2013.

LONDOÑO, X. Distribucion, Morfologia, Taxonomia, Anatomia, Silvicultura y usos de los Bambues del Nuevo Mundo. III Congreso Colombiano de Botanica, Popayan, 7-12 de Noviembro. 25p. 2004.

LONDOÑO, X. Two new Guadua species for Peru (Poaceae: Bambusoideae: Bambuseae: Guaduinae). Journal of the Botanical Research. Inst. Texas v.7. pp. 145-153. 2013.

LONDOÑO, X.; PETERSON, P.M. Guadua chacoensis (Poaceae: Bambuseae), Its Taxonomic Identity, Morphology, and Affinities. Novon. vol. 2(1). pp. 414.1992.

LONGHI-WAGNER, H.M. Poaceae: an overview with reference to Brazil. Rodriguésia. v.36. pp. 89-100. 2012.

METCALFE, C. R. Anatomy of the Monocotyledons. I. Gramineae. Oxford University Press. Amen House. Londres, 1960.

MIRANDA, A.F.A. Estudo anatômico do entrenó de Guadua Kunth (Poaceae: Bambusoideae) ocorrentes no estado do Acre/Brasil. Dissertação. Programa de Pós-Graduação em Botânica, Universidade de Brasília. 2016.

ALVES, G.T.R. Aspectos da história de vida de Guadua Tagoara (Ness) Kunth (Poaceae: Bambuseae) na Serra dos órgãos, RJ. Dissertação. Programa de Pós-Graduação em Ecologia e Recursos Naturais, Universidade Federal de São Carlos. 2007.

MOTA, A. C.; OLIVEIRA, R. P.; CLARK, L. G. Chusquea clemirae (Bambusoideae: Poaceae): a new woody bamboo from the montane Atlantic rainforest of Bahia State, Brazil. Systematic Botany. v.38. pp. 92-96. 2014. 
NADGAUDA, R. S.; PARASHARAMI, V. A.; MASCARENHAS, A. F. "Precocious flowering and seeding behavior in tissue-cultured bamboos". Nature. v.344. pp. 335-336. 1990.

NELSON, B. W.; BIANCHINI, M. C. Complete life cycle of southwest Amazon bamboos (Guadua spp.) detected with orbital optical sensors. In: Anais XII Simpósio Brasileiro de Sensoriamento Remoto, Goiânia, Brasil, 16-21 abril, INPE, pp. 1629-1636. 2005.

OLIVEIRA, R. P.; CLARK, L. G. A tiny new Brazilian species of Diandrolyra (Poaceae: Bambusoideae: Olyreae), with notes on the systematics of the genus. Novon. v.19. pp. 209-214. 2009.

OLIVEIRA, R.P.; LONGHI-WAGNER, H.M.; LEITE, K.R.B. A contribuição da anatomia foliar para a taxonomia de Raddia Bertol. (Poaceae: Bambusoideae).

Acta Botanica Brasilica. v.22(1). pp.1-19. 2008.

OLIVIER, J.; OTTO, T.; RODDAZ, M.; ANTOINE, P.; LONDOÑO, X.; CLARK, L. $G$. First macrofossil evidence of a pre-Holocene thorny bamboo cf. Guadua (Poaceae: Bambusoideae: Bambuseae: Guaduinae) in south-western Amazonia (Madre de Dios - Peru). Review of Palaeobotany and Palynology. Elsevier Scientific Publications. v.153. pp.1-7. 2009.

PEREIRA, M.A.R.; BARATA, T.Q.F. Bamboo as sustainable material used in design and civil construction: species, management, characterization and applications. Key Engineering Materials. v. 634. pp. 339-350. 2015.

ROLIM, R. G.; SETUBAL, R. B.; CASAGRANDE, A.; RIVAS, M. I. E.; DE NARDIN, J. A.; PROENÇA, M. L.; SANDRIL, S. M.; BONILHA, C. L.; BOLDRINI, I. I. Composição e estrutura de vegetação campestre em áreas com orientação norte e sul no Jardim Botânico de Porto Alegre, RS, Brasil. Iheringia Série Botânica. v.69(2). pp. 433-449. 2014.

RUIZ-SANCHÉS, E.; SOSA, V.; MEIJÍA-SAULES, M.T. Molecular phylogenetics of the Mesoamerican bamboo Olmeca (Poaceae, Bambuseae): Implications for taxonomy. Táxon. v.60(1). pp. 89-98. 2011.

SALGADO, A.L.B. Bambu com sal: Aqui e agora, lá e então. Ed. Amaro Comunicação. $1^{\text {a }}$ ed. 322p. 2014.

SANTOS-GONÇALVES, A.P.; CARVALHO-OKANO, R.M.; FILGUEIRAS, T.S. A new species of Merostachys (Poaceae: Bambusoideae) from South eastern Brazil. Systematic Botany. v.37. pp. 938-940. 2012.

SANTOS-GONÇALVEZ, A. P.; FILGUEIRAS, T. S.; CLARK, L.G. Atractantha shepherdiana, a New Speciesof Woody Bamboo (Poaceae: Bambusoideae: Bambuseae) from Brazil. The American Society of Plant Taxonomists. Systematic Botany. v.36(2). pp. 310-313. 2011.

SHIRASUNA, R.T. Guadua in Lista de Espécies da Flora do Brasil. Jardim Botânico do Rio de Janeiro. Disponível em: $<$ http://floradobrasil.jbrj.gov.br/jabot/floradobrasil/F B13247>. 2015. Acesso em: 13 Fev. 2016. 
SILVA, I. F.; PEREIRA, D. S.; SILVA, S. R. F. Estudos Morfológicos do Bambu (Bambusa cf. vulgaris L.), uma espécie invasora em área de Mata Atlântica no Parque Municipal de Maceió-Alagoas. Revista Semente. v.6(6). pp. 99-109. 2011.

SNOW, N. The Phylogenetic Utility of Lemmatal Micromorphology In Leptochloa S.L. and Related Genera In Subtribe Eleusininae (Poaceae: Chloridoideae, Eragrostideae). In: Annals of the Missouri Botanical Garden. v.83(4). pp. 504-529. 1996.

SODERSTROM, T. R. Sucrea (Poaceae: Bambusoideae), a New Genus from Brazil. Brittonia. v.33(2). pp. 98-210. 1981.

SODERSTROM, T. R; ELLIS, R. P. The position of bamboo genera and allies in a system of grass classification. In Grass Systematics and evolutionds. T.R. Doderstrom, K.W. Hilu, C.S. Campbell, and M.E. Barkworth. Washington DC: Smithsonian Institution Press. pp. 225-238. 1987.

SODERSTROM, T.R.; JUDIZIEWICZ, E.J.; CLARK, L.G. Distribuition patterns of Neotropical Bamboos. In: Vanzolini, P.E.; Heyer, R.E. (eds.). Proceedings of a Workshop on Neotropical Distribution Patterns. Academia Brasileira de Ciências, Rio de Janeiro. pp. 121-157. 1988.

SORENG, R.J.; PETERSON, P.M.; ROMASCHENKOL, K.; DAVIDSE, G.; ZULOAGA, F.O.; JUDZIEWICZ, E.J.; FILGUEIRAS, T.S. DAVIS, J.I.; MORRONE, O. A worldwide phylogenetic classification of the Poaceae (Gramineae). Journal of Systematics and Evolution. 2015.

SOTO, M.M.L.; KOCH, S.D.; FLORES-CRUZ, M.; ENGLEMAN, M. Anatomía comparrada de la lamína foliar del género Distichlis (Poaceae). Acta Botanica Mexicana. v.89. pp. 1-23. 2009.

STEVENS, P. F. Angiosperm Philogeny Website. Versão 13. Disponível em http://www.mobot.org/MOBOT/research/APweb. Acesso em 16 ago. de 2016.

SUNGKAEW, S.; STAPLETON, C. M. A.; SALAMIN, N.; R. H. TREVOR. Nonmonophyly of the woody bamboos (Bambuseae; Poaceae): a multi-gene region phylogenetic analysis of Bambusoideae. Journal of Plant Research. v.122. pp 95-108. 2009.

SYLVESTER, S.P. An illustrated generic key and updated list of the grasses (Poaceae) of Belize. Edinburgh Journal of Botany. pp.1-43. 2016.

THE ANGIOSPERM PHYLOGENY GROUP APG III. An update of the Angiosperm Phylogeny Group classification for the orders and families of flowering plants. Botanical Journal of the Linnean Society. v.161. pp. 105121. 2009. 
TRUONG, A.H.; LE, T.M.A. Overview of bamboo biomass for energy production. Sciences de l'Homme et de la Société. 2014.

VIANA, P.L.; FILGUEIRAS, T.S.; CLARK, L.G. Cambajuva (Poaceae: Bambusoideae: Bambuseae: Arthrostylidinae), a new woody bamboo genus from Southern Brazil. Systematic Botany. v. 38. Pp. 97-103. $2013 a$.

VIANA, P. L.; FILGUEIRAS, T. S.; GRACIANO-RIBEIRO, D. A new woody bamboo (Poaceae: Bambusoideae) from Central Brazil. Novon. v.22. pp. 371376. 2013b.

WELKER, C. A. D.; LONGHI-WAGNER, H. M. A família Poaceae no Morro Santana, Rio Grande do Sul, Brasil. Revista Brasileira de Biociências. v.5(4). pp. 53-92. 2007.

YEASMIN, L.; ALI, M.N.; GANTAIT, S.; CHAKRABORTY, S. Bamboo: an overview on its genetic diversity and characterization. Biotech. v.5(1). pp.1-11. 2015.

YOUNG, S. M.; JUDD. W. S. Systematics of the Guadua angustifolia Complex (Poaceae: Bambusoideae). Annals of the Missouri Botanical Garden. v.79(4). pp. 737-769. 1992.

ZHAO, H.; PENG, Z.; SUN, H.; YUE, X.; LOU, Y.; DONG, L .; WANG, L.; GAO, Z. Developing genome-wide microsatellite markers of bamboo and their applications on molecular marker assisted taxonomy for accessions in the genus Phyllostachys. Scientific Reports. v.5. pp.1-10. 2015.

ZHOU, H.F.; LI, S.S.; GE, S. Isolation and characterization of microsatellite loci for a bioenergy grass, Miscanthus sacchariflorus (poaceae). Applications in Plant Sciences. v.1 ( 1 ). 2013.

FLORA DO BRASIL 2020 em construção. Jardim Botânico do Rio de Janeiro. Disponível em: http://floradobrasil.jbrj.gov.br/reflora/floradobrasil/FB13247>. Acesso em: 27 Jan. 2017. 


\section{CAPÍTULO 01}

Aspectos epidérmicos e micromorfológicos da superfície foliar de populações de Guadua Kunth (POACEAE: BAMBUSODEAE: GUADUINAE) ocorrentes no Brasil 


\section{RESUMO}

O Brasil tem uma grande diversidade de bambus, cerca 234 espécies. Dentre os Bambuseae um dos gêneros mais conhecidos é Guadua. São bambus lignificados, com presença marcante de espinhos, uma faixa de tricomas brancos na região nodal e folhas do colmo de formato triangular. Os longos ciclos de vida e floração gregária são a maior dificuldade encontrada na realização de estudos sobre a taxonomia das espécies desses bambus. Estudos com caracterizações anatômicas e micromorfológicas da lâmina foliar de populações Guadua são escassos e diante disso o presente trabalho buscou analisar os aspectos da anatomia e micromorfologia da epiderme foliar de dez populações de Guadua a fim de auxiliar na caracterização do gênero e obter dados que possam auxiliar em sua posterior delimitação. As amostras foram coletadas em diferentes localidades. Para secções paradérmicas porções da lâmina foliar foram submetidas à solução de Franklin adaptada; corados em solução de azul de metileno com ácido bórico e montados em resina sintética. Para análises micromorfológicas os fragmentos de folhas seguiram metodologia usual para microscopia eletrônica de varredura. As terminologias utilizadas para as descrições seguiram principalmente Metcalfe (1960), Ellis (1979), Graciano-Ribeiro et al. (2006), e Santos et al. (2010). As zonas costais e intercostais são distinguíveis. Nas zonas costais em ambas as faces ocorrem células longas, silicificadas, suberosas, bem como macro e microtricomas. Nas zonas intercostais ocorrem células longas, silicificadas, raras células suberosas, estômatos, macro e microtricomas em ambas as faces. Papilas: recobrem todas as células em ambas as faces, exceto as silicificadas e não foram observadas em três das dez populações analisadas. Células buliformes: exclusivamente adaxiais e possuem papilas. Células longas: de formatos retangulares com paredes fortemente sinuosas. As papilas cobrem os estômatos formando câmaras na face adaxial e apenas os rodeiam na face abaxial. Células silicificadas: são frequentes e em geral apresentam formato sela, ocorrendo também as de formato halteres, altas estreitas e nodulares. Células suberosas: são frequentes, de formato crenado, e sempre que ocorrem estão em pares com as silicificadas. Estômatos: possuem tamanhos variados, quanto aos formatos das células subsidiárias são classificados em cúpula, paralelos ou arredondados e triangular. Macrotricomas: de tamanhos variados e ápice afunilado. Microtricomas: formato bastão, geralmente ocorrem na zona intercostal e são bicelulares de tamanhos variados. Espinhos: possuem a base dilatada, também rodeada por papilas, diferem dos ganchos pelo formato do ápice: ganchos com ápice recurvado, e espinhos com ápice reto. A caracterização da epiderme foliar nos revelam semelhanças entre as populações de Guadua estudadas com outras populações analisadas por outros autores. Não foram observados microtricomas em duas das dez populações estudadas, e considerando que a presença de microtricomas é citada como sinapomorfia em Bambusoideae, tais populações necessitam de mais análises, com maior número amostral. Esse estudo contribuiu para salientar a importância da análise anatômica da epiderme, tanto para a caracterização quanto para a taxonomia das populações de bambu, principalmente ocorrentes no Brasil.

Palavras-chave: Bambu lignificado; Epiderme da lâmina foliar; Micromrfologia. 


\section{INTRODUÇÃO}

Os bambus estão entre as Poaceae mais complexas, quanto à morfologia e anatomia dos órgãos vegetativos (ELLIS, 1979; SODERSTROM et al., 1988). Bambusoideae crescem associados à vegetação lenhosa, ocorrendo normalmente em florestas tropicais e subtropicais do mundo (SODERSTROM, 1981). As espécies florestais destacam-se pelo grande número de representantes, sendo os da tribo Olyreae bambus herbáceos e da tribo Bambuseae os lignificados (ZHANG \& CLARK, 2000; GPWG, 2001; GPWG, 2012; KELCHNER \& BPG, 2013).

O continente americano ocupa o segundo lugar em abundância de espécies de bambu, perde apenas para a Ásia. Dentre os países americanos, o Brasil tem a maior diversidade de espécies, cerca de 34 gêneros divididos em 234 espécies (FILGUEIRAS \& SANTOS-GONÇALVES, 2004).

Bambusoideae diferem das demais gramíneas na anatomia das folhas por apresentarem: mesofilo homogêneo composto por células invaginantes e fusoides; mais que um feixe vascular na nervura central, e as células silicificadas estão orientadas verticalmente (SODERSTROM \& ELLIS, 1987).

Dentre Bambuseae um dos gêneros mais conhecidos é Guadua, apresenta importância ecológica, social, econômica e cultural (LONDOÑO, 2002; GALVÃO et al., 2012; GRECO \& CROMBERG, 2011). No Brasil Guadua está representado por cerca de 21 espécies (SHIRASUNA, 2015). São bambus lignificados, com presença marcante de espinhos na base dos nós, faixas de tricomas brancos na região dos nós e folhas caulinares de formato triangular. Seus colmos podem atingir de 20 a $30 \mathrm{~m}$ de altura e diâmetro variando de $20 \mathrm{a}$ $25 \mathrm{~cm}$. Em relação aos usos destacam-se principalmente Guadua angustifolia Kunth e Guadua chacoensis (Rojas) Londoño \& P. M. Peterson (LINDHOLM \& PALM, 2007).

Os longos ciclos de vida e floração gregária são a maior dificuldade encontrada na realização de estudos sobre a taxonomia das espécies de bambus lignificados. Nesse sentido Soderstrom \& Ellis (1987) apontam que os caracteres anatômicos facilitam a distinção de Bambusoideae do restante das 
gramíneas, porém a identificação de gêneros e espécies ainda apresenta dificuldades taxonômicas.

Estudos com caracterizações micromorfológicas de espécies Guadua ainda são escassos (MONTIEL et al., 2006a; 2006b; 2006c; MARQUEZ et al., 2011; PANIZZO et. al., 2016).

Diante de tal fato, o presente trabalho buscou analisar os aspectos da anatomia e micromorfologia da epiderme foliar de 10 populações de Guadua, a fim de auxiliar na caracterização do gênero e obter caracteres de valor taxonômico que possam auxiliar na sua delimitação.

\section{MATERIAL E MÉTODOS}

Amostras das folhas da ramificação foram coletadas em diferentes localidades (tabela 01). Foi selecionada a terceira folha, totalmente expandida, contando do ápice para a base do ramo, de três indivíduos em cada população e armazenadas em etanol $70 \%$ + glicerina 50\% (JENSEN, 1962). Foram confeccionadas exsicatas dos materiais vegetais obtidos e depositadas no herbário da Universidade Federal de Goiás.

Para secções paradérmicas porções da lâmina foliar foram submetidas à solução de Franklin (FRANKLIN, 1945), adaptada. Alocadas em estufa a $70^{\circ} \mathrm{C}$ por até 72 horas. Os fragmentos de epiderme foram corados em solução de azul de metileno (1\%) com ácido bórico (1\%) na proporção de 1:1, e montados em resina sintética (PAIVA et al., 2006).

Para análises micromorfológicas os fragmentos de folhas foram desidratados em série acetonica crescente (70-100\%), levadas ao sonicador a $37^{\circ} \mathrm{C}$ por cerca de uma hora em cada concentração a fim de retirar o excesso de cera presente nas lâminas foliares. Em seguida foram secos ao ponto crítico com $\mathrm{CO}_{2}$ líquido, aderidos em porta espécime (Stubs) e posterior metalização com ouro (BOZZOLA \& RUSSEL, 1992). Foram observados em microscópio eletrônico de varredura JEOL JSM-7001F do Laboratório de Microscopia Eletrônica do Departamento de Biologia Celular da Universidade de Brasília. As terminologias utilizadas para as descrições seguiram principalmente Metcalfe (1960), Ellis (1979), Graciano-Ribeiro et al. (2006), e Santos et al. (2010). 


\section{RESULTADOS}

Em vista frontal temos ZONAS COSTAIS e INTERCOSTAIS distinguíveis (fig. 1 e 2). Nas zonas costais em ambas as faces ocorrem células longas, silicificadas, suberosas, bem como macro e microtricomas. Nas zonas intercostais ocorrem células longas, silicificadas, raras células suberosas, estômatos, macro e microtricomas em ambas as faces. Na face adaxial temos ainda as células buliformes.

\section{Face abaxial}

CÉLULAS LONGAS: apresentam formatos retangulares, são mais compridas do que largas, geralmente separadas por células silicificadas na zona costal; são recobertas por papilas, em maior quantidade na face adaxial, não permitindo que maiores detalhes sejam observados em microscopia eletrônica de varredura. Em microscopia óptica observa-se células longas, com paredes celulares periclinais fortemente sinuosas e espessas, e as paredes anticlinais côncavas (fig. 2).

PAPILAS: Ocorrem nas zonas costais e intercostais, recobrem todas as células em ambas as faces, exceto as silicificadas; são abundantes e encontram-se em maior densidade em G. paniculata e G. sp. 02. São globosas com distribuição organizada em uma ou duas fileiras; quanto aos formatos podem ser: simples, bifurcadas ou ramificadas (fig 03), de tamanhos variados. Não foram observadas em G. magna, G. cf. magna e G. virgata (fig. 2).

CÉLULAS SILICIFICADAS: são frequentes e estão dispostas em fileiras na zona costal e estão entre as células longas na região intercostal, são mais frequentes na zona costal. Em geral apresentam formato sela alta ou arredondada, ocorrendo também as de formato halteres, alta e estreita, e ainda de contorno ou forma nodular (fig. 5d-h).

CÉLULAS SUBEROSAS: São frequentes, apresentam formato crenado, e sempre que ocorrem estão em pares com as silicificadas, sendo que nem todas as silicificadas estão acompanhadas por suberosas (fig. $5 \mathrm{~g} \mathrm{e} \mathrm{h}$ ). 
ESTÔMATOS: são frequentes em G. sp. 01e G. sp. 02, e abundantes em G. paniculata, G. refracta, G. cf refracta, G. magna, G. cf magna e G. virgata. Possuem tamanhos variados, e quanto aos formatos das células subsidiárias são classificados como: paralelas e/ou arredondadas observados em todas as espécies; em formato de cúpula em G. sp 01, G. magna e G. cf. magna, e também formato triangular em $G$. magna e $G$. virgata. Na maioria das espécies ocorrem papilas exceto em G. magna, G. cf. magna e G. virgata (fig. 6). As papilas podem estar dispostas ao redor dos estômatos, sobre as células guarda e células subsidiárias. O número de papilas ao redor dos estômatos difere entre as espécies, 6-12 papilas em G. paniculata; 7-12 em G. sp01; e 812 G. refracta, G. cf. refracta e G. sp02.

CÉLULAS INTERESTOMÁTICAS: Em microscopia óptica as células interestomáticas se mostraram retangulares a quadradas com paredes periclinais e anticlinais sinuosas (fig. 2). São recobertas por papilas que dificultam a visualização em microscopia eletrônica de varredura.

MACROTRICOMAS: unicelulares, apresentam tamanhos variados, com ápice afunilado; quanto à base, podemos classificar em dois tipos: dilatado em relação à espessura total e não dilatado (fig. $7^{\text {a }}$ e b). As papilas envolvem a base de todos os macrotricomas das espécies que possuem papilas. Quanto à localização foram observados apenas na região costal em $G$. refracta, $G$. cf refracta, G. sp. 02 e G. virgata; em ambas as regiões (costal e intercostal) em G. paniculata e G. magna, embora sejam raros nessa última espécie; e apenas na região intercostal em G. cf magna.

MICROTRICOMAS: Geralmente ocorrem na zona intercostal, são bicelulares com tamanhos variados e formato classificado como "bastão" (fig. 7c e d). Quanto à localização ocorrem apenas na zona costal em G. paniculata, G. sp. 02 e G. virgata; e em ambas as regiões (costal e intercostal) em G. refracta, $G$. cf refracta e G. sp. 01. Em algumas espécies foi difícil observá-los inteiros, pois a célula distal apresenta a parede fina sendo facilmente danificada e perdida. Não observados em G. magna e G. cf. magna (fig. 3 e 4).

ESPINHOS- "Prickle-hairs": Possuem a base dilatada, também rodeadas por papilas, e ápice afunilado, ocorrem em todas as espécies (fig. $7 \mathrm{~d}$ e f). Diferem 
dos ganchos pelo formato do ápice, ganchos com ápice recurvado (fig. $7 \mathrm{~g}$ e h), e espinhos com ápice reto. Quanto à localização, foram observados em ambas as regiões - costal e intercostal - em todas as espécies, exceto em G. magna e G. cf magna, nas quais são raros e ocorrem apenas na zona costal.

\section{Face adaxial}

Apresenta basicamente os mesmos tipos celulares da face abaxial (fig. 1 e 4), com exceção das células buliformes.

CÉLULAS BULIFORMES: Restritas à face adaxial na zona intercostal, estão dispostas em fileiras com formatos que variam de retangulares a quadradas com paredes celulares espessas em todas as espécies. Nestas células ocorrem papilas, exceto em G. magna, G. aff. magna e G. virgata (fig. 3).

CÉLULAS LONGAS: apresentam o mesmo formato que na face abaxial, são recobertas por papilas, no entanto em maior quantidade que na face abaxial, não permitindo que maiores detalhes sejam observados (fig. 1).

CÉLULAS SILICIFICADAS: apresentam os mesmos formatos observados na face abaxial, predominando o formato sela nas zonas costais e halteres, meia lua ou em forma de rim nas zonas intercostais (fig. $5 d-h$ ), sendo que são mais difíceis de serem observadas na zona intercostal devido à presença dos estômatos.

PAPILAS: São abundantes, apresentam os mesmos formatos que na face abaxial, e se diferenciam por estarem recobrindo os estômatos formando uma câmara (fig. 5a-c; 6a-f).

Microtricomas, ganchos e espinhos ocorrem em menor quantidade, e apresentam os mesmos formatos que na face abaxial. Os espinhos e ganchos na maioria das espécies são observados apenas na região intercostal, próximos as células buliformes, e na espécie G. sp. 2) também podem ocorrer na região costal. Enquanto os microtricomas estão localizados nas zonas 
intercostais sempre próximos as células buliformes. Não foram observados em G. magna, G. aff. magna e G. virgata.

ESTÔMATOS: ocorrem em menor quantidade que na superfície abaxial, e são cobertos por papilas. O número de papilas por estômato varia de 7-15 formando uma câmara totalmente fechada ou parcialmente fechada (fig. 6 a-f).

\section{DISCUSSÃO}

A caracterização da epiderme foliar mostrou semelhanças entre as populações de Guadua estudadas, as células epidérmicas estão distribuídas em zona costal e intercostal, as folhas são anfihipoestomáticas com estômatos arranjados em bandas bem definidas na região intercostal, caracteres designados por Ellis (1979) e Metcalfe (1960) como sendo o padrão para Poaceae. Assim como células longas, células silicificadas dispostas transversalmente, células suberosas, células buliformes, microtricomas, espinhos, ganchos e papilas são considerados como padrão típico observado em Bambusoideae (Metcalfe, 1960; Renvoize, 1987; Judziewcz et al., 1999).

As células longas apresentam paredes celulares espessas e sinuosidades irregulares, conforme verificado por Brandis (1907) em bambus e outras gramíneas. O mesmo foi observado em G. angustifolia f. atlântica (Montiel et al., 2006c).

Papilas ocorrem em todas as células da epiderme em ambas as faces, exceto nas silicificadas. A presença de papilas em ambas as faces, principalmente associadas aos estômatos, é citada por Londoño (2002) como um dos caracteres que diferenciam Guadua de outros gêneros. No entanto, a ausência dessa estrutura em três das oito populações aqui analisadas nos 
instiga a ampliar o número de espécies a fim de determinar se essa característica é realmente distintiva para o gênero, uma vez que Lizarazu et al. (2013) verificaram também a ausência de papilas em ambas as faces de $G$. angustifolia Kunth, G. calderoniana Londonõ \& Judz, G. chacoensis (Rojas) Londoño \& P.M. Peterson, G. macclurei R.W. Pohl \& Davidse, G. tagoara Kunth, G. trinii (Nees) Nees. ex. Rupr., G. uncinata Londono \& L. G. Clark e G. variegata Lizarazu. Assim como Montiel et al. (2006a; 2006b; 2006c; 2006d) em três variedades de G. angustifolia, em G. macclurei e G. amplexifolia J. Presl. coletadas na Costa Rica; e Panizzo (2016) observou a ausência de papilas em G. chacoensis coletada na Argentina. Salienta-se abundantes papilas em G. paniculata em ambas as faces, fato também observado por Montiel et al. (2006a). Em todas as espécies ocorrem estômatos em ambas as faces, o que é usual dentro da subtribo Guaduineae (Soderstrom \& Ellis, 1987). Quanto ao formato dos estômatos, foram observados os tipos triangular, cúpula e paralelo, sendo possível identificar a ocorrência de mais de um tipo na mesma folha, assim como cita Metcalfe (1960). Sendo que G. magna e G. aff. magna apresentam os três tipos, as demais apresentam estômatos paralelos e em cúpula, exceto G. virgata com apenas o tipo cúpula, como observado por Lizarazu (2013) em G. variegata e G. macclurei (Montiel et al., 2006b).

A presença de papilas associadas aos estômatos é um aspecto importante na sistemática dos bambus, principalmente para Guaduineae (Soderstrom \& Ellis, 1987). Em cinco das populações analisadas as papilas estão associadas aos estômatos formando um tipo de câmara totalmente fechada ou parcialmente fechada na face adaxial e ao redor na face abaxial, e em três populações $G$. magna, $G$ aff. magna e G.virgata estão ausentes. 
Lizarazu (2013) também observou variações nas espécies analisadas, com ocorrência em ambas as faces (G. paniculata), somente na face adaxial ( $G$. paraguayana, G. sarcocarpa e G. ciliata) e ausente em G. angustifolia, G. calderoniana, G. macclurei, G. tagoara, G. trinii e G. variegata. Esses resultados reforçam a necessidade de mais estudos na subtribo para elucidar o valor desse caracter.

Células silicificadas em forma de sela e halteres, dispostas transversalmente, foram citadas por Renvoize (1987) para Bambusoideae. Os formatos predominantes nas populações de Guadua aqui estudadas foram sela e halteres, além destes, também foram observados os formatos altas estreitas e nodulares, complementando as informações do autor supracitado. Segundo Metcalfe (1960) e Piperno \& Pearsall (1998), além de ser uma importante característica na família Poaceae, os formatos das células silicificadas podem ser amplamente utilizados para auxiliar a taxonomia, por não sofrerem variações de formato advindas do ambiente. Lizarazu (2013) observou apenas o formato halter em G. variegata. Os resultados mostram que houve um predomínio dos tipos halter e sela citados para o gênero, e o tipo nodular o qual ainda não foi citado em estudos anteriores.

As funções das células silicificadas estão relacionadas com solucionar problemas de balanço hídrico, refletância de radiação solar na epiderme. Conferem também uma barreira ao ataque de patógenos e dão reforço mecânico às estruturas vegetativas (Motomura et al., 2004). A maior ocorrência das células silicificadas na face adaxial reforça essa hipótese. 
Os microtricomas observados são constituídos por duas células (bicelulares) chamados de bastão por Tateoka et al. (1959), sendo que microtricomas unicelulares também podem ser observados em algumas Poaceae (Alvares, 2005), já Montiel et al. (2006b) verificaram microtricomas tricelulares para a espécie G. macclurei da Costa Rica, essas variações não foram observadas nas populações em estudo. Não foram observados microtricomas em duas populações estudadas: G. magna e em G. aff. magna. Considerando que a presença de microtricomas é citada por Judziewicz et al. (1999) como sinapomorfia em Bambusoideae, tais espécies necessitam de mais análises a fim de reforçar os resultados aqui inferidos.

Conforme Metcalfe (1960) e Judziewcz et al. (1999) os bambus podem ter macrotricomas unicelulares e alongados em uma ou em ambas as faces da lâmina foliar. Os macrotricomas variaram em comprimento e espessura, ocorrendo nas zonas costais, intercostais, sobre a nervura central e na margem foliar. Segundo Santos et al. (2010) são comuns variações na densidade dos macrotricomas entre espécies de gramíneas bem como variações entre indivíduos de uma mesma população. Sabe-se, no entanto, que a observação deste caráter depende do processo de preparo das lâminas, pois parte dos tricomas pode ser perdido. Montiel et al. (2006c) relata a ocorrência de tricomas unicelulares na zona costal da face abaxial em $G$. angustifolia $f$. atlântica e ausência em G. angustifolia f. sur. Estão ausentes também em G. amplexifólia na face abaxial (2006d).

Estudos realizados por Montiel et al. (2006a; 2006b; 2006c; 2006d) analisando a ultraestrutura das espécies G. angustifolia var. Atlántica", "Sur" e "Cebolla", G. macclurei, G. paniculata, e Guadua amplexifolia J. Presl. 
verificaram basicamente as mesmas características descritas neste estudo, acrescentando ainda a ausência de macrotricomas em G. angustifolia var Cebolla e G. angustifolia var sur; raros ganchos e espinhos em G. amplexifolia, caracteres também observadas por Panizzo et al. (2016) para G. chacoensis.

\section{Relação com o ambiente}

Para Ellis (1979) as paredes fortemente sinuosas das células longas são resultados do estresse sofrido pela planta durante o desenvolvimento da folha, ainda segundo os autores, tal adaptação decorre dos movimentos de expansão

e contração das folhas durante os processos de entrada e saída de água, assim, as sinuosidades estão envolvidas na proteção contra o murchamento, evitando o colapso paredes celulares. Nesse sentido, é importante para plantas que crescem sob alta incidência luminosa e baixa disponibilidade de água, como é o caso de algumas populações deste estudo. Todavia, as espécies $G$. magna, G. aff. magna, G. aff. refracta e G. virgata foram coletadas em beira de córrego e também apresentaram células longas com paredes sinuosas.

Segundo Dickison (2000) a baixa disponibilidade hídrica pode causar grandes variações nas características anatômicas das folhas em geral, e na estrutura epidérmica tais variações podem se revelar como alterações na densidade de tricomas, papilas e conformidade das células epidérmicas comuns.

A função das papilas sobre a epiderme foliar ainda não foi totalmente estabelecida, entretanto Judziewicz et al. (1999) associaram a densidade destas como um recurso da planta a diferentes condições ambientais tais como 
temperatura, umidade e incidência de luz solar, sendo provável que nas populações de Guadua aqui estudadas as papilas também realizem função de proteção juntamente com as células silicificadas evitando, assim, o superaquecimento e consequente ressecamento das folhas. Visto que as três populações em que as papilas não foram observadas foram coletadas em zona de mata de galeria em beira de córrego, podemos concordar com o autor ao associar a ocorrência e densidade destas com a disponibilidade de água no ambiente.

A abundância das células silicificadas nas populações estudadas concordam com as afirmações de Motomura et al. (2004) ao relacionar a ocorrência dessas células com a refletância da radiação solar na epiderme, conferem também uma barreira ao ataque de patógenos e reforço mecânico das estruturas foliares. 


\section{CONSIDERAÇÕES FINAIS}

As espécies estudadas apresentaram características epidérmicas comuns as já conhecidas para Poaceae e Bambusoideae, algumas podem estar relacionadas a ambientes xeromórficos como: abundância de tricomas e papilas, células longas com paredes sinuosas, e estômatos recobertos por papilas. Sugere-se que estas características estejam relacionadas à economia de água diante de variações ambientais que possam ocorrer durante 0 desenvolvimento destas plantas, visto que cinco das populações foram coletadas em beira de estrada, ambientes com alta incidência luminosa.

Os resultados mostram que a ausência de papilas na epiderme em ambas as faces da folha verificadas em G. magna, G. cf magna e G. virgata são caracteres que podem delimitar estas populações.

Podemos concluir que caracteres anatômicos da epiderme, são informativos e importantes para a relação taxonômica em espécies Guadua, características como a ocorrência e o formato das células silicificadas na epiderme e a abundância de papilas já foram citadas para outras espécies pertencentes à Guadua. No entanto a ausência de papilas em algumas espécies tanto neste estudo quanto no de outros autores, sugerem que tal característica deva ser mais estudada para todas as espécies do gênero, visto que o ambiente pode ter influência sobre o desenvolvimento dessas estruturas. 


\section{REFERÊNCIAS BIBLIOGRÁFICAS}

ALVAREZ, J.M.; ROCHA, J.F.; MACHADO, S.R. Estrutura foliar de Loudetiopsis chrysothrix (Nees) Conert e Tristachya leiostachya Nees (Poaceae). Revista Brasileira de Botânica. v.28, n.1. p. 23-37, 2005.

BOZZOLA, J. J.; RUSSEL, L. D. Electron Microscopy: Principles and Techniques for Biologists. Boston: Jones \& Batlett Publisher. pp.340-450, 1992.

BRANDIS, S.D. Remarks on the Struture of Bamboo Leaves. Transactions of the Linnean Society of London. v.2(7). pp. 69-92. 1907.

ELLIS, R.P. A procedure for standardizing comparative leaf anatomy in the Poaceae. I. The leaf-blade as viewed in transverse section. Bothalia. v.12. pp. 65-109. 1976.

ELLIS, R.P. A procedure for standardizing comparative leaf anatomy in the Poaceae II: The epidermis as seen in surface view. Bothalia. v.12. pp. 641671. 1979.

FILGUEIRAS, T. S. \& SANTOS-GONÇALVES, A. P. A cheklist of the basal grasses and bamboos in Brazil. Bamboo Science and Culture, v. 18, n. 1, p. 7-18. 2004.

FRANKLIN, G.L. Preparation of thin seccions of syntetic resins and wood-resin composites, and a new macerating method for wood. Nature. v.155(51). 1945.

GALVÃO, F.; AUGUSTIN, G.R.C.; COSMO, N.; KOZERA, C.; DOMANOWSKI, B.P.; SAWCZUK, T.A. Impacto de Guadua paraguayana sobre remanescente de floresta ombrófila mista aluvial - Uma abordagem biogeoquímica. Floresta. v.42(2). pp. 355-368. 2012.

GPWG (Grass Phylogeny Working Group). New grass phylogeny resolves deep evolutionary relationships and discovers C4 origins. New Phytologist. v.193. pp. 304- 312. 2012.

GPWG, Phylogeny and subfamilial classification of the grasses (Poaceae). Annals of the Missouri Botanical Garden. v.88. pp. 373-457. 2001.

GRACIANO-RIBEIRO, D.; FILGUEIRAS, T. D; SANTOS-GONÇALVES, A. P. Roteiro Mínimo para Estudo Anatômico dos Bambus (Poaceae: Bambusoideae). In: Anais do I Seminário Nacional do Bambu. Brasília-DF, set. 2006.

GRECO, T. M.; CROMBERG, M. Bambu cultivo e manejo. 1. Ed. Florianópolis. SC: Insular. 184 p. 2011.

JENSEN, W. A. Botanical Histochemistry: principles and practices. São Francisco: W.H. Freeman, 1962. 
JUDZIEWICZ, E. J.; CLARK, L. G.; LONDOÑO, X. \& STERN, M. J. American bamboos. Washignton, D. C., Smithsonian Institution Press, 392 pp, 1999.

JUDZIEWICZ, E. J.; CLARK. L. G. Classification and biogeography of New World grasses: Anomochlooideae, Pharoideae, Ehrhartoideae, and Bambusoideae. Aliso: A Journal of Systematic and Evolutionary Botany. v. 23. p. 303-314. 2007.

KELCHNER, S.A.; BPG. Higher level phylogenetic relationships within the bamboos (Poaceae: Bambusoideae) based on five plastid markers. Molecular Phylogenetics and Evolution, v. 67, p. 404-413. 2013.

LINDHOLM, M.; PALM, S. Guadua chacoensis in Bolivia an investigation of mechanical properties of a bamboo species. Linköping, Department of Management and Engineering Centre for Wood Technology \& Design. Pp.127. 2007.

LIZARAZU, M.A.; RÚGULO DE AGRASAR, Z.E.; VEGA, A.S. A New Species of Guadua (Poaceae, Bambusoideae, Bambuseae) and Synopsis of the Genus in Argentina and Neighboring Regions. Systematic Botany. v. 38. pp. 10621075, 2013.

LONDOÑO, X. Distribuição, morfologia, taxonomia, anatomia, floresta e usos bambus do novo mundo. Cadeira de Mestrado em Construção - Modulo Guadua, Arquitetura, da Universidade Nacional da Colômbia, Bogotá, 2002. Disponível em: http://www.hof-landlust.de/scb/taller.html. Acesso em 10 ago. 2016.

MÁRQUEZ, L.; GARCÍA, M.; DOUGLAS, M. Anatomía foliar de Guadua angustifolia Kunth, G. amplexifolia PRESL. Y Elytrostachys typica Mcclure (POACEAE, BAMBUSOIDEAE). Ernstia. v. 21. pp. 91-109, 2011.

METCALFE, C. R. Anatomy of the Monocotyledons. I. Gramineae. Oxford University Press. Amen House. Londres, 1960.

MONTIEL, M. GUEVARA, E.; JIMÉNEZ, V.M. Ultraestructura del bambú Guadua paniculata (Poaceae: Bambusoideae) de Costa Rica. Revista Biologia Tropical. V. 54. p. 29-34, 2006a.

MONTIEL, M.; GUEVARA, E.; JIMÉNEZ, V.M. Ultraestructura del bambú Guadua macclurei (Poaceae: Bambusoideae) de Costa Rica. Revista Biologia Tropical. v. 54. p. 35-42, $2006 \mathrm{~b}$.

MONTIEL, M.; JIMÉNEZ, V.M.; GUEVARA. E. Caracterización anatómica ultraestructural de tres variaciones de la especie de bambú Guadua angustifolia, "Atlántica", "Sur" y "Cebolla", en Costa Rica. Revista Biologia Tropical. v. 54. p. 1-12, 2006c.

MONTIEL, M.; JIMÉNEZ, V.M.; GUEVARA. E. Ultraestructura del bambú Guadua amplexifolia (Poaceaea: Bambusoideae) presente en Costa Rica. Revista Biologia Tropical. v. 54. p. 21-28, 2006d. 
MOTOMURA, H.; FUJII, T.; SUZUKI, M. Sílica deposition in relation to ageing of leaf tissues in Sasa veitchii (Carrière) Rehder (Poaceae: Bambusoideae). Annals of Botany. v. 93. p. 235-248. 2004.

PAIVA, J.G.A.; FRANK-DE-CARVALHO, S.M; MAGALHÃES, M.P.; GRACIANO-RIBEIRO, D. Verniz vitral incolor 500®: uma alternativa de meio de montagem economicamente viável. Acta Botânica Brasílica. v.20(2). Pp. 257264. 2006.

PANIZZO, C.C.; FERNANDEZ, P.V. COLOMBATTO, D. CIANCIAB, M.; VEGA, A.S. Anatomy, nutritional value, and cell wall chemical analysis of foliage leaves in Guadua chacoensis (Poaceae: Bambusoideae: Bambuseae), a promising source of forage. 2016.

PIPERNO, D.R.; PEARSALL, D.M. The Silica Bodies of Tropical American Grasses: Morphology, Taxonomy, and Implications for Grass Systematics and Fossil Phytolith Identification In: Smithsonian contributions to botany. Washington, D.C.: Smithsonian Institution Press. v. 85. pp.1-40. 1998.

PRAT, H. La Sistématique des Graminées. Annales des Sciences Naturelles Botanique. Ser., 10(18). p. 165-257. 1936.

RENVOIZE, S.A. A survey of leaf-blade anatomy in grasses IV: Eragrostideae. Kew Bulletin. v.38(3). pp. 469-478. 1983.

SANTOS, S. A; DESBIEZ, A. L. J; MAGALHÄES, J. A; GARCIA, J. B; SOBRINHO, A. A. B, Descritores epidérmicos de gramíneas: um guia para identificação da dieta de herbívoros usando o programa Delta. Boletim de Pesquisa. Embrapa Pantanal Boletim de Pesquisa e Desenvolvimento (Centro de Pesquisa Agropecuária do Pantanal), Centro de Pesquisa Agropecuária do Pantanal v. 95, p. 1-64. 2010.

SHIRASUNA, R.T. Guadua in Lista de Espécies da Flora do Brasil. Jardim Botânico do Rio de Janeiro. Disponível em: <http://floradobrasil.jbrj.gov.br/jabot/floradobrasil/FB13247>. 2015.

SODERSTROM, T.R. \& ELLIS, R.P. The position of bamboo genera and allies in a system of grass classification. In: Grass Systematic Evolution, eds T.R. Soderstrom, K.W. Hilu, C.S. Campbell \& M.E. Barkworth: Smithsonian Institution. p. 225-238, 1987.

SODERSTROM, T.R.; JUDIZIEWICZ, E.J.; CLARK, L.G. Distribuition patterns of Neotropical Bamboos. In: Vanzolini, P.E.; Heyer, R.E. (eds.). Proceedings of a Workshop on Neotropical Distribution Patterns, 1988.

TATEOKA, T.; SUKEMITSO, I.; KAWANO, S. Systematic Significance of Bicellular Microhairs of Leaf Epidermis. Botanical Gazette. v.121. p.80-91, 1959.

ZHANG, W. \& CLARK, L.G. Phylogeny and classification of the Bambusoideae (Poaceae). In: S.W.L. Jacobs \& J. Everert (eds.). Grass Systematics and Evolution. Melbourne, CSIRO, 2000. 
Tabela 01: Lista de espécies de Guadua Kunth. Estudadas com os respectivos locais, data de coleta, coordenadas, coletores e número de coleta.

\begin{tabular}{|c|c|c|c|c|c|}
\hline Espécie & Local & Data & Coordenadas & Coletores & $\begin{array}{l}\text { № de } \\
\text { coleta }\end{array}$ \\
\hline $\begin{array}{c}\text { Guadua cf. } \\
\text { magna }\end{array}$ & $\begin{array}{c}\text { Reserva do } \\
\text { Cabaçal - } \\
\text { MT }\end{array}$ & $\frac{0}{\frac{0}{\infty}}$ & $\begin{array}{c}15^{\circ} 06^{\prime} 003^{\prime \prime} \mathrm{S} \\
058^{\circ} 28^{\prime} 500 " \mathrm{~W}\end{array}$ & $\begin{array}{l}\text { Graciano- } \\
\text { Ribeiro et } \\
\text { al. }\end{array}$ & 428 \\
\hline $\begin{array}{l}\text { Guadua cf. } \\
\text { refracta }\end{array}$ & Brasília - DF & 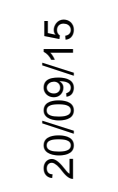 & $\begin{array}{c}15^{\circ} 94^{\prime} 284 " \mathrm{~S} \\
047^{\circ} 61^{\prime} 886^{\prime \prime} \mathrm{W}\end{array}$ & $\begin{array}{l}\text { Graciano- } \\
\text { Ribeiro et } \\
\text { al. }\end{array}$ & 419 \\
\hline $\begin{array}{c}\text { Guadua } \\
\text { chacoensis } \\
\text { (Rojas) Londoño } \\
\text { \& P.M. Peterson }\end{array}$ & $\begin{array}{l}\text { Senador } \\
\text { Canedo - } \\
\text { GO }\end{array}$ & $\frac{n}{\frac{n}{2}}$ & $\begin{array}{c}16^{\circ} 72^{\prime} 087^{\prime \prime S} \\
049^{\circ} 13^{\prime} 259^{\prime \prime W}\end{array}$ & $\begin{array}{l}\text { Graciano- } \\
\text { Ribeiro et } \\
\text { al. }\end{array}$ & 399 \\
\hline $\begin{array}{l}\text { Guadua magna } \\
\text { Londoño \&Filg. }\end{array}$ & $\begin{array}{l}\text { Itaguari - } \\
\text { GO }\end{array}$ & 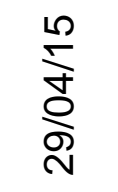 & $\begin{array}{c}15^{\circ} 56^{\prime} 482^{\prime \prime S} \\
049^{\circ} 35^{\prime} 656^{\prime \prime} \mathrm{W}\end{array}$ & $\begin{array}{l}\text { Graciano- } \\
\text { Ribeiro et } \\
\text { al. }\end{array}$ & 398 \\
\hline $\begin{array}{c}\text { Guadua } \\
\text { paniculataMunro }\end{array}$ & $\begin{array}{c}\text { Cavalcante - } \\
\text { GO }\end{array}$ & 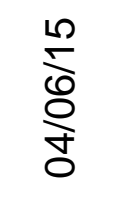 & $\begin{array}{c}13^{\circ} 28^{\prime} 74.3^{\prime \prime S} \\
047^{\circ} 57^{\prime} 71.7^{\prime \prime W}\end{array}$ & $\begin{array}{l}\text { Graciano- } \\
\text { Ribeiro et } \\
\text { al. }\end{array}$ & 405 \\
\hline $\begin{array}{c}\text { Guadua refracta } \\
\text { Munro }\end{array}$ & $\begin{array}{l}\text { BR } 020 \text { Km } \\
\quad 44 \\
\text { Brasília - DF }\end{array}$ & $\begin{array}{l}\stackrel{n}{\infty} \\
\text { o } \\
\stackrel{0}{\circ}\end{array}$ & $\begin{array}{c}15^{\circ} 22 ' 247^{\prime \prime S} \\
047^{\circ} 06^{\prime} 169 " W\end{array}$ & $\begin{array}{l}\text { Graciano- } \\
\text { Ribeiro et } \\
\text { al. }\end{array}$ & 416 \\
\hline Guadua sp. 01 & $\begin{array}{c}\text { Estrada } \\
\text { para } \\
\text { Curvelândia } \\
\text { - MT }\end{array}$ & 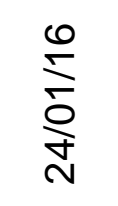 & $\begin{array}{c}15^{\circ} 34^{\prime} 055^{\prime \prime} \mathrm{S} \\
057^{\circ} 56^{\prime} 592^{\prime \prime} \mathrm{W}\end{array}$ & $\begin{array}{l}\text { Graciano- } \\
\text { Ribeiro et } \\
\text { al. }\end{array}$ & 425 \\
\hline Guadua sp. 02 & $\begin{array}{l}\text { Figueirópolis } \\
\text { - MT }\end{array}$ & $\frac{0}{\frac{0}{\infty}}$ & $\begin{array}{c}15^{\circ} 24^{\prime} 519 " \mathrm{~S} \\
058^{\circ} 37^{\prime} 529^{\prime \prime} \mathrm{W}\end{array}$ & $\begin{array}{l}\text { Graciano- } \\
\text { Ribeiro et } \\
\quad \text { al. }\end{array}$ & 429 \\
\hline Guadua sp. 03 & $\begin{array}{l}\text { Goiânia - } \\
\text { GO }\end{array}$ & $\begin{array}{l}\frac{10}{\hbar} \\
\stackrel{0}{0} \\
0\end{array}$ & - & $\begin{array}{l}\text { Graciano- } \\
\text { Ribeiro et } \\
\text { al. }\end{array}$ & 400 \\
\hline $\begin{array}{l}\text { Guadua virgata } \\
\text { (Trin.) Rupr. }\end{array}$ & Arinos - MG. & 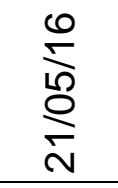 & $\begin{array}{c}15^{\circ} 53 \text { '096"S } \\
046^{\circ} 20^{\prime} 737^{\prime \prime W}\end{array}$ & $\begin{array}{l}\text { Cunha- } \\
\text { Santana } \\
\text { et al. }\end{array}$ & 435 \\
\hline
\end{tabular}




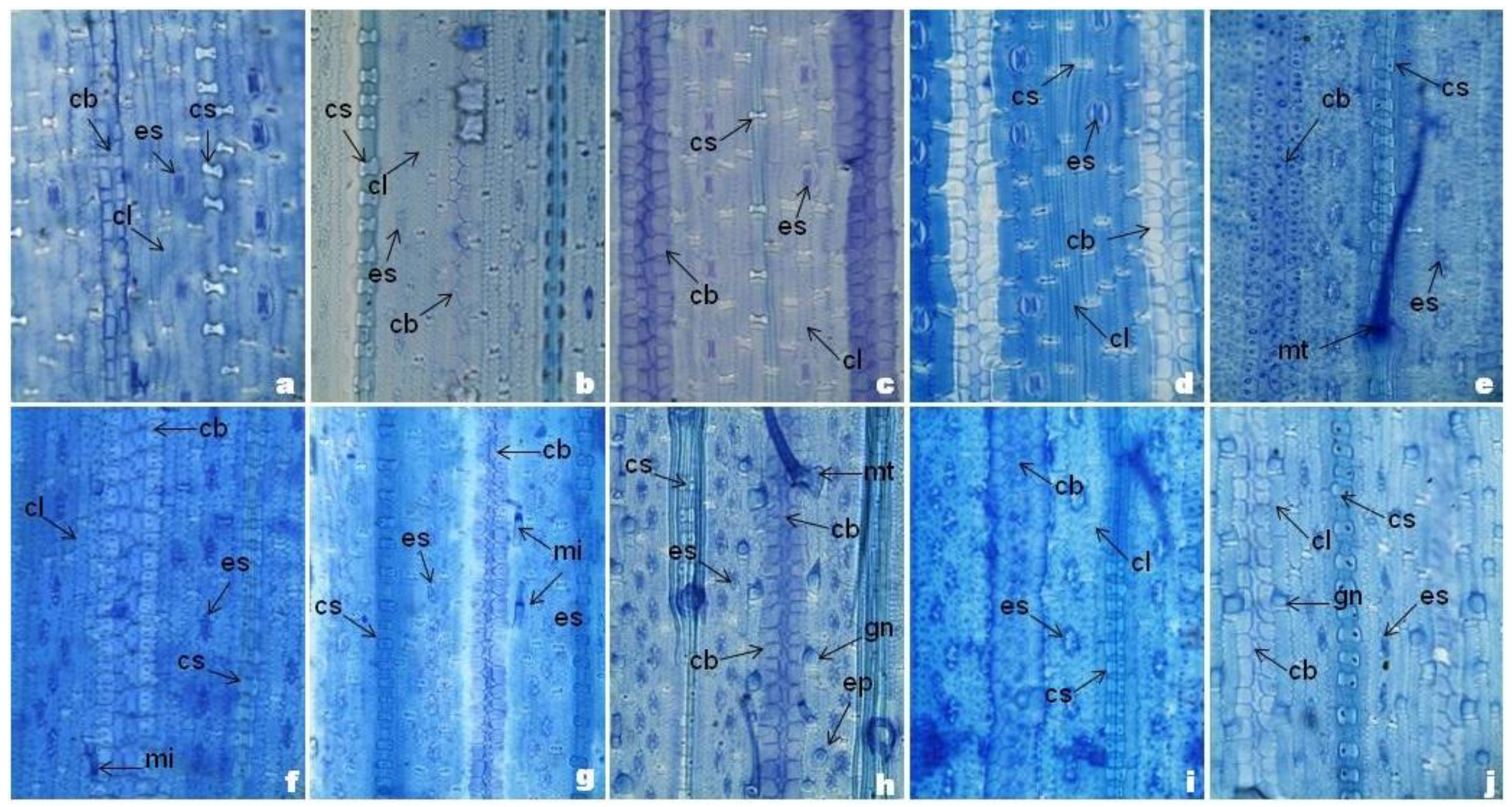

Figura 01: Superfície foliar das populações de Guadua estudadas evidenciando a face adaxial. a: G. cf magna; b: G. cf refracta; c: G. chacoensis; d: G. magna; e: G. paniculata; f: G. refracta; g: G. sp 01; h: G. sp 02; i: G. sp 03; j: G. virgata. cb: células buliformes; es: estômato; cs: célula silicificada. cl: célula longa; mt: macrotricoma; mi: microtricoma; ep: espinho; gn: gancho. Aumento: $100 \mu \mathrm{m}$. 


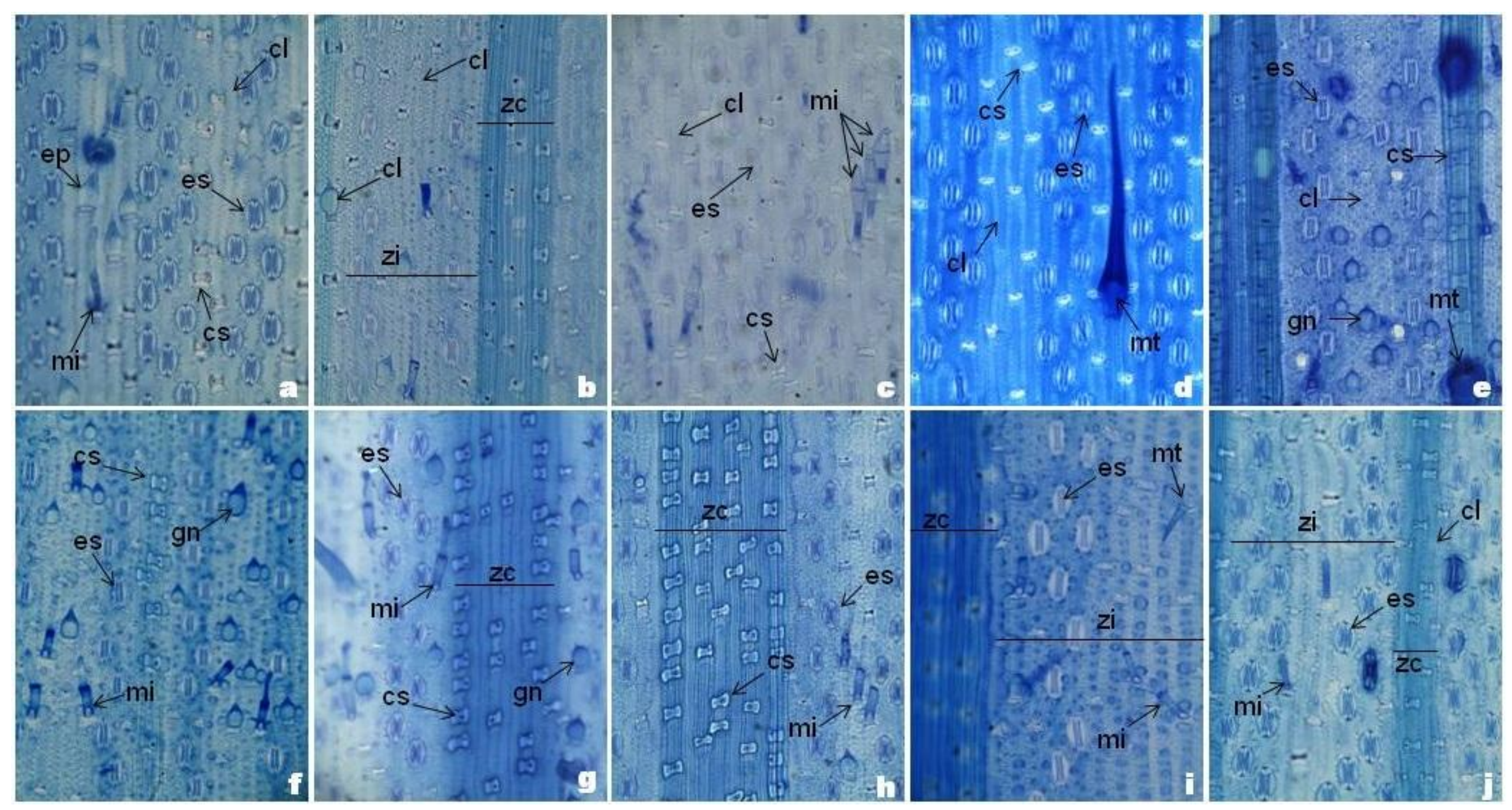

Figura 02: Superfície foliar das populações de Guadua estudadas evidenciando a face abaxial. a: G. cf magna; b: G. cf refracta; c: G. chacoensis; d: G. magna; e: G. paniculata; f: G. refracta; g: G. sp 01; h: G. sp 02; i: G. sp 03; j: G. virgata. zc: zona costal; zi: zona intercostal; cb: células buliformes; es: estômato; cs: célula silicificada. cl: célula longa; mt: macrotricoma; mi: microtricoma; ep: espinho; gn: gancho. Aumento: 100um. 

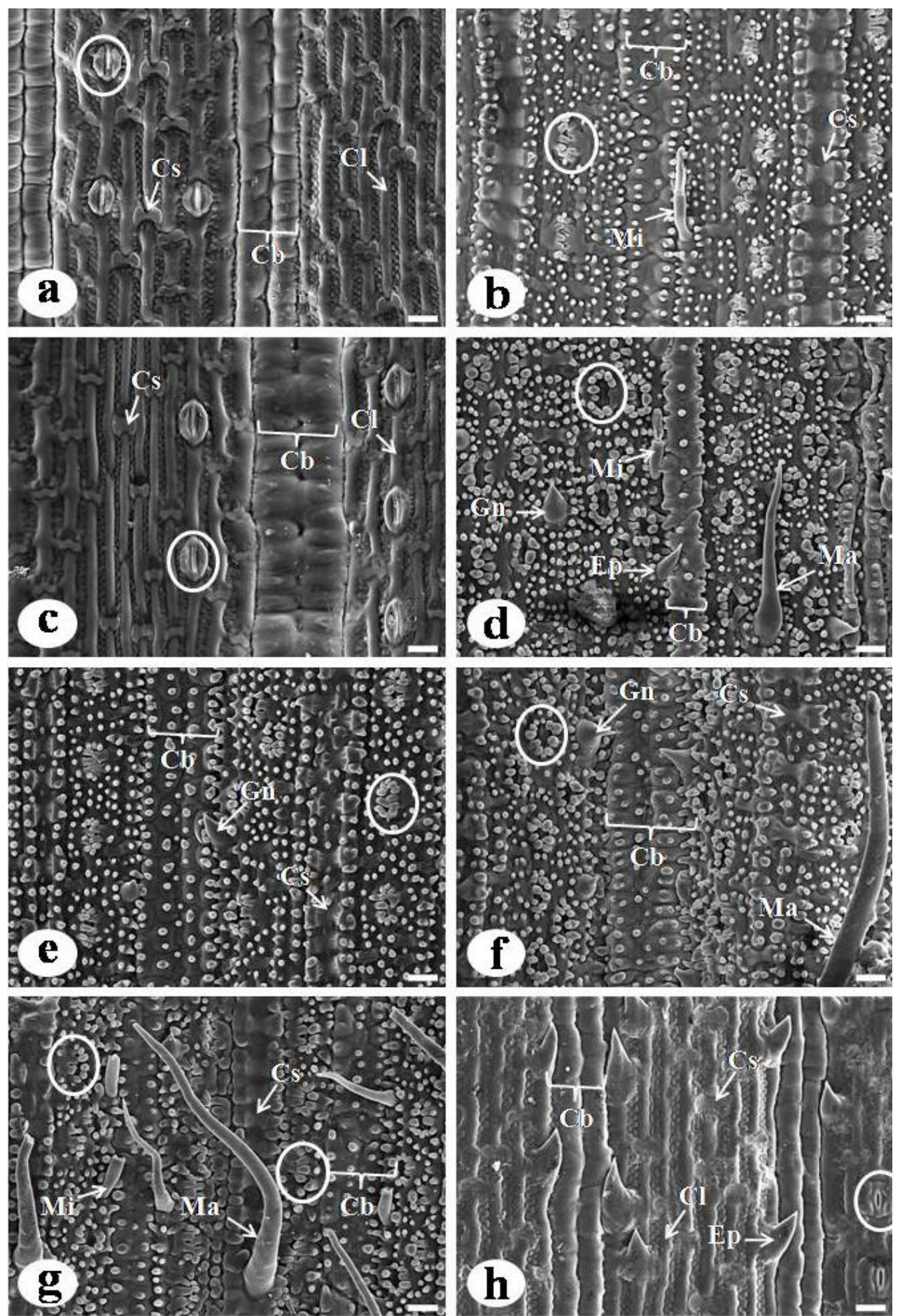

Figura 3: Epiderme adaxial das populações de Guadua Kunth estudadas, vistas em microscopia eletrônica de varredura, evidenciando a organização e disposição das células. a: $G$. aff. magna; b: $G$. aff. refracta; c: $G$. magna; d: $G$. paniculata; e: $G$. refracta; f: G. sp. 1; g: G. sp. 2; h: G. virgata . Zc: zona costal; Zi: zona intercostal; Cs: célula silicificada; Es: estômato; Ep: espinhos; Mi: microtricomas; Ma: macrotricomas; $\mathrm{Ci}$ : células invaginantes. $\mathrm{Zc}$ : zona costal; $\mathrm{Zi}$ : zona intercostal; $\mathrm{Cb}$ : células buliformes; Cs: célula silicificada; Es: estômato; Ep: espinhos; Mi: microtricomas; Ma: macrotricomas; $\mathrm{Ci}$ : células invaginantes; círculos demarcam os estômatos. círculos mostram os estômatos. Barra $=100 \mu \mathrm{m}$ 

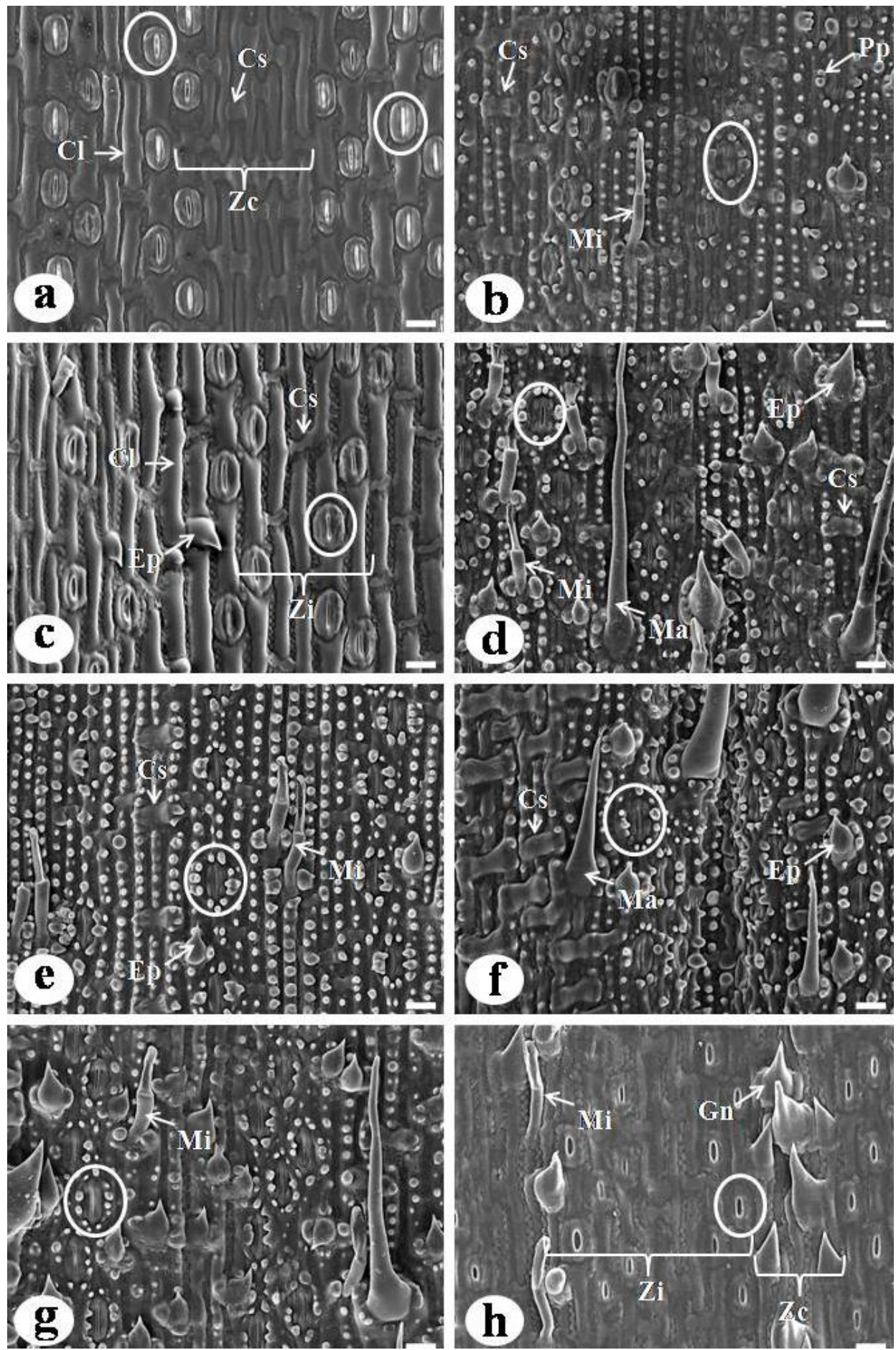

Figura 4: Epiderme abaxial das populações de Guadua Kunth estudadas, vistas em microscopia eletrônica de varredura, evidenciando a organização e disposição das células. a: $G$. aff. magna; b: $G$. aff. refracta; c: $G$. magna; d: $G$. paniculata; e: $G$. refracta; f: $G$. sp. $1 ;$ g: $G$. sp. 2 ; h: G. virgata . Zc: zona costal; Zi: zona intercostal; Cs: célula silicificada; Es: estômato; Ep: espinhos; Mi: microtricomas; Ma: macrotricomas; Ci: células invaginantes; círculos demarcam os estômatos. Barra $=100 \mu \mathrm{m}$. 


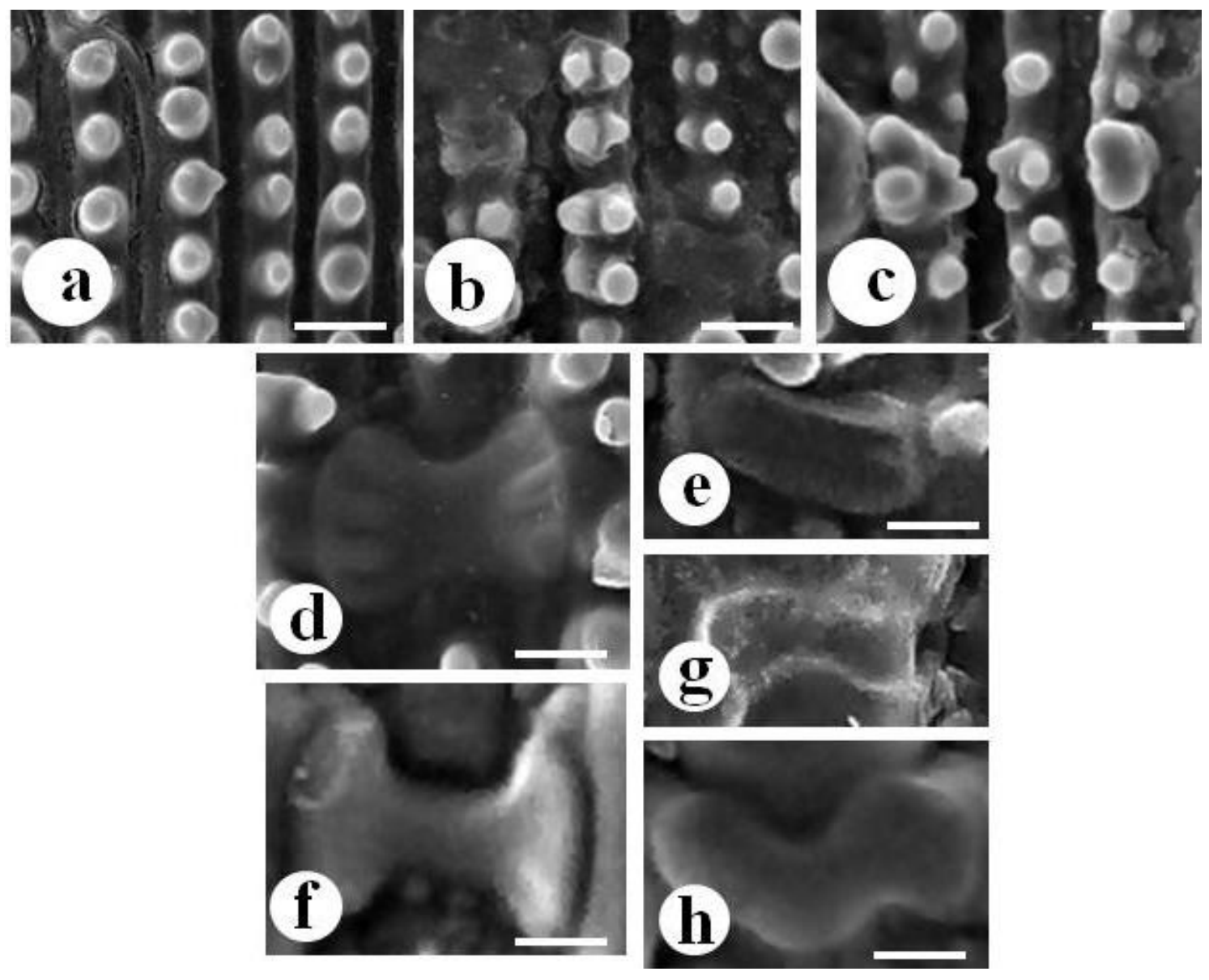

Figura 5: Detalhes das estruturas celulares: papilas e células silicificadas. a: papilas simples; b: papilas bifurcadas; c: papilas ramificadas. d: célula silicificada de formato sela; e: célula silicificada de formato arredondado; f: célula silicificada de formato halter; g: célula silicificada de formato reniforme; h: célula silicificada de formato nodular. Barra $=100 \mu \mathrm{m}$. 

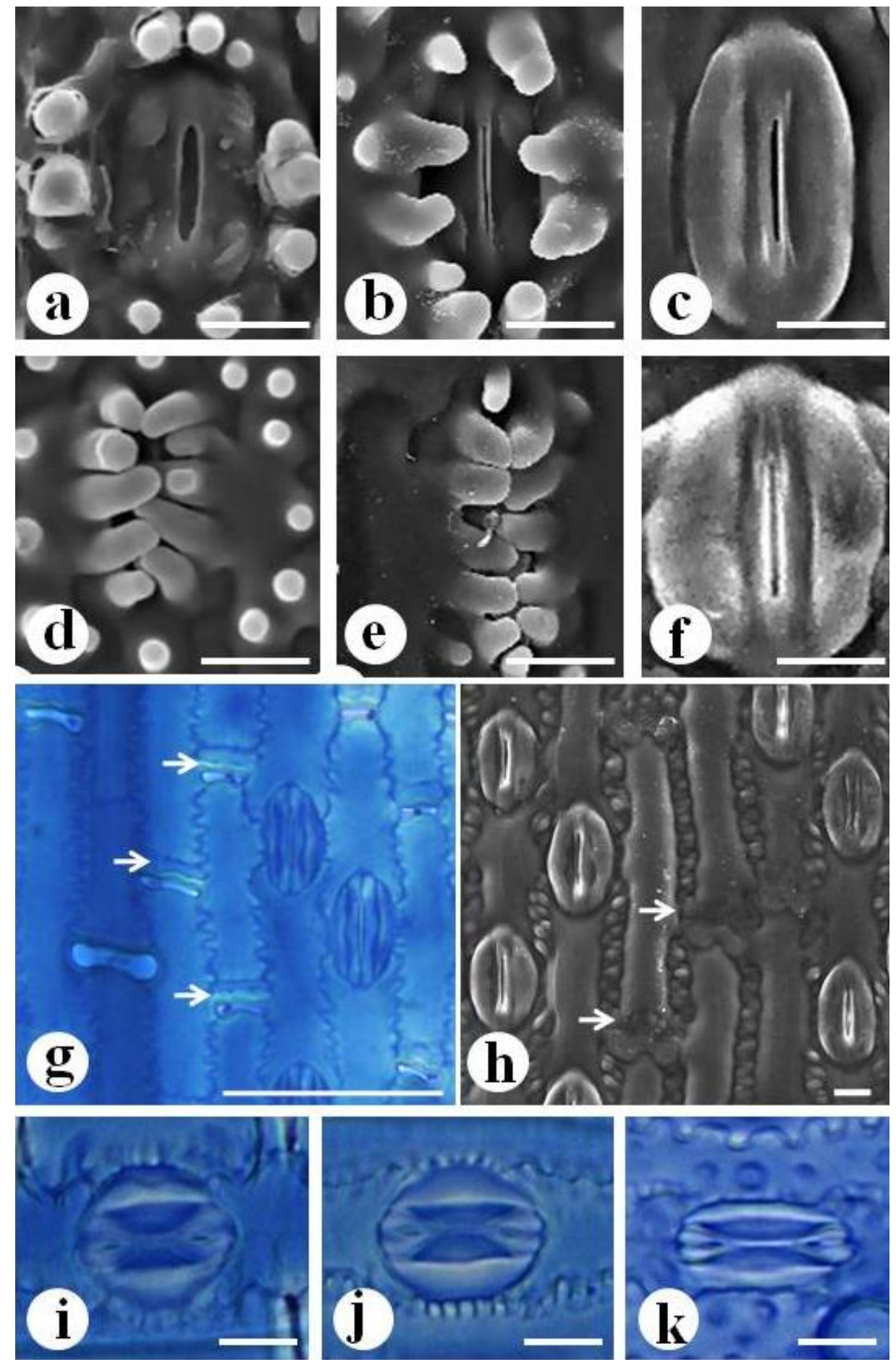

Figura 6: Detalhe dos estômatos observados nas populações de Guadua estudadas. a; b: superfície abaxial, estômatos rodeados por papilas; c: estômato abaxial com papilas ausentes em G. magna. d, e: superfície adaxial papilas formando câmara protetora; f: estômato adaxial com papilas ausentes em $G$. aff. magna. Barra $=100 \mu \mathrm{m}$. $\mathbf{g}$, h: detalhe das células suberosas aos pares com as silicificadas; $\mathrm{i}$ : estômato de formato cúpula; $\mathrm{j}$ : estômato de formato triangular; k: estômato de formato paralelo. 


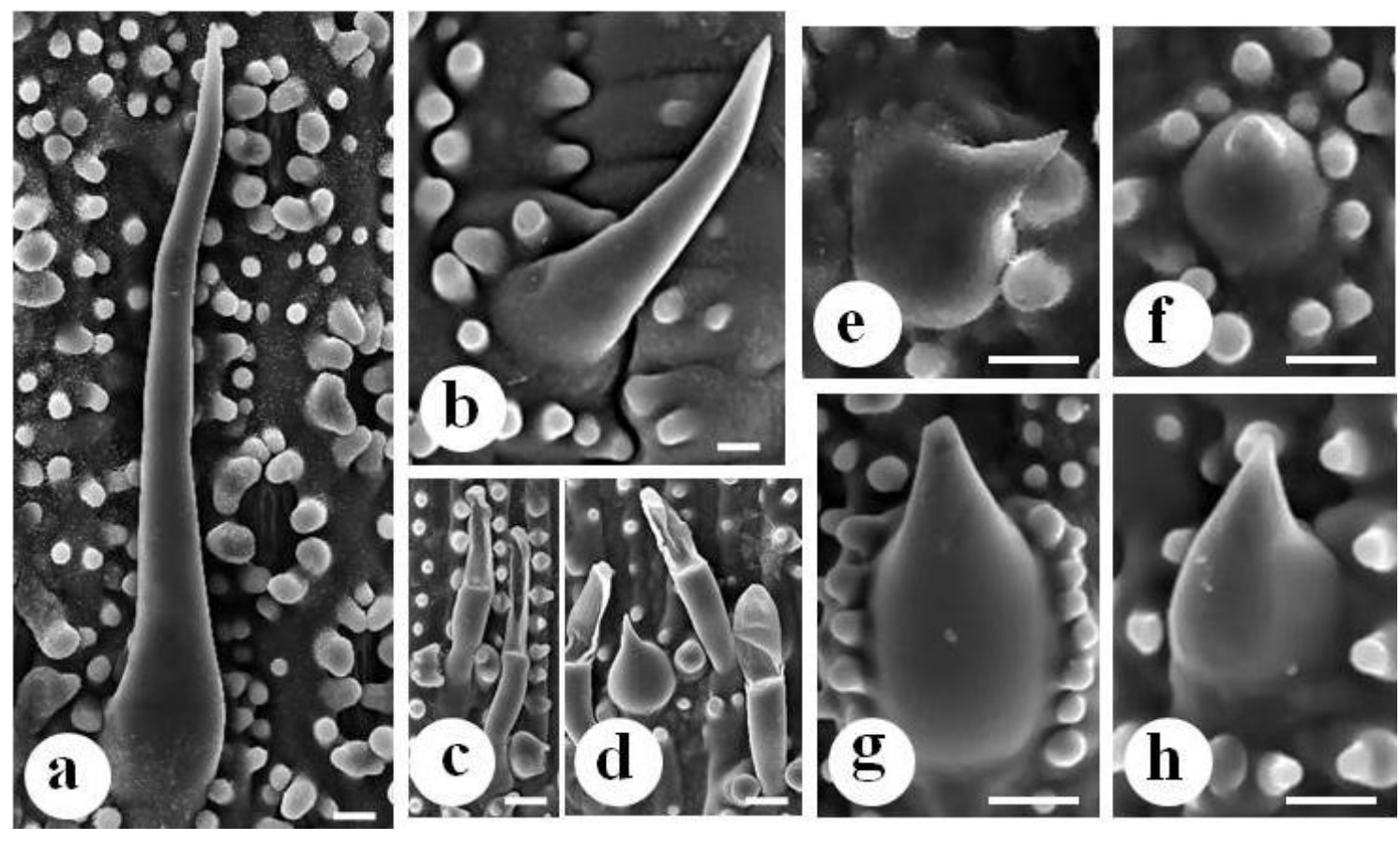

Figura 7. Detalhe dos tricomas vistos em microscopia eletrônica de varredura. a: macrotricoma longo com base envolta por papilas; b: macrotricoma curto, com a base recoberta por papilas; c, d: microtricomas bicelulares; e, f: espinhos com base dilatada e ápice reto; g, h: ganchos com base dilatada, envolta por papilas e ápice recurvado. Barra $=100 \mu \mathrm{m}$. 


\section{CAPÍTULO 02}

Aspectos anatômicos em secção transversal da lâmina foliar de populações

Guadua Kunth (POACEAE: BAMBUSODEAE: GUADUINAE) ocorrentes no Brasil 


\section{INTRODUÇÃO}

A subfamília Bambusoideae é dividida em: Olyreae, bambus herbáceos, Bambuseae bambus lignificados tropicais e Arundinarieae bambus lignificados de clima temperado (ZHANG \& CLARK, 2000; LONDOÑO, 2004). Bambuseae é a mais numerosa e de ampla distribuição. Dentre Bambuseae temos Guadua Kunth. O gênero foi descrito por Kunth (1822) apud Londoño e Peterson (1992), reúne bambus neotropicais lignificados com espinhos, pertencentes à subtribo Guaduinae que engloba também os gêneros: Olmeca Soderstr, Otatea (McClure \& E.W.Sm.) C.E. Calderón \& Soderstr, Eremocaulon Soderstr. \& Londoño e Apoclada McClure (SODERSTROM \& LONDOÑO, 1987; JUDZIEWICZ et al., 1999; LONDOÑO \& CLARK, 2002; RUIZ-SANCHEZ et al., 2008; 2011).

Constituem um grupo monofilético (RUIZ-SANCHEZ et al., 2008; FISHER et al., 2009), contém cerca de 28 espécies e ocorrem em toda a América tropical, do México para o norte da Argentina (LONDOÑO \& PETERSON, 1992), apresentando sua maior diversidade na região amazônica da Bolívia, Brasil, Colômbia, Equador, Peru e Venezuela (LONDOÑO, 2013).

Importantes caracteres diagnósticos que distinguem este gênero de outros bambus são colmos lignificados, folhas do colmo triangulares, nas quais as margens da bainha e da lâmina são contíguas, e possuem uma faixa de tricomas brancos curtos acima e/ou abaixo da linha nodal; quanto a anatomia apresentam grande número de estômatos em ambas as superfícies das folhas (JUDZIEWICZ et al., 1999) e abundantes papilas em torno dos estômatos adaxiais (JUDZIEWICZ \& CLARK, 2007).

Guadua, assim como outros bambus lignificados, possui floração do tipo gregária e monocárpica, devido a esse padrão os indivíduos geralmente são encontrados em sua fase vegetativa, dificultando assim a identificação das espécies (CARVALHO, 2009). Com isso a identificação de novos caracteres anatômicos tem um importante significado taxonômico, contribuindo para a determinação do material vegetativo (GUERREIRO et al., 2013). 
Os trabalhos taxonômicos sobre Bambus devem incluir informações sobre anatomia, pois esta constitui uma ferramenta básica para os sistemas de classificação (LONDOÑO \& Clark, 2004).

O presente estudo buscou analisar em secção transversal os aspectos da anatomia foliar de 10 populações de Guadua Kunth a fim de buscar dados que possam auxiliar na caracterização do gênero.

\section{MATERIAL E MÉTODOS}

\section{Material vegetal}

Amostras das folhas da ramificação foram coletadas em diferentes localidades (tabela 01). Foi selecionada a terceira folha, totalmente expandida, contando do ápice para a base do ramo, de três indivíduos em cada população e armazenadas em etanol 70\% + glicerina 50\% (JENSEN, 1962). Foram confeccionadas exsicatas dos materiais vegetais obtidos e depositadas no herbário da Universidade Federal de Goiás.

\section{Estudo anatômico}

Foram feitas secções transversais à mão livre na região mediana das folhas coletadas, em seguida clarificadas com hipoclorito de sódio $20 \%$ e $50 \%$ respectivamente (KRAUS \& ARDUIN, 1997), e submetidas à dupla coloração com azul de astra 1\% e safranina 1\% (3:1), as lâminas permanentes foram montadas em lâmina e lamínula utilizando resina sintética (PAIVA et al., 2006).

As fotomicrografias foram obtidas com auxílio de microscópio ótico Leica DM 500 com câmara digital (Leica ICC50) acoplada e software LAS EZ versão 1.8.1. As descrições anatômicas seguiram de acordo com Metcalfe (1960), Ellis (1976) e Graciano-Ribeiro et al. (2006). 
Tabela 01: Lista de espécies de Guadua Kunth coletadas com localidade, data, coordenadas, coletores e número de coleta.

\begin{tabular}{|c|c|c|c|c|c|}
\hline Espécie & Local & Data & Coordenadas & Coletores & $\begin{array}{l}\text { № de } \\
\text { coleta }\end{array}$ \\
\hline $\begin{array}{c}\text { Guadua cf. } \\
\text { magna }\end{array}$ & $\begin{array}{c}\text { Reserva do } \\
\text { Cabaçal - } \\
\text { MT }\end{array}$ & 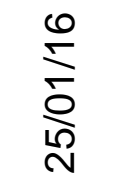 & $\begin{array}{c}15^{\circ} 06^{\prime} 003^{\prime \prime} \mathrm{S} \\
058^{\circ} 28^{\prime} 500^{\prime \prime} \mathrm{W}\end{array}$ & $\begin{array}{l}\text { Graciano- } \\
\text { Ribeiro et } \\
\quad \text { al. }\end{array}$ & 428 \\
\hline $\begin{array}{l}\text { Guadua cf. } \\
\text { refracta }\end{array}$ & Brasília - DF & $\begin{array}{l}\frac{10}{2} \\
\text { ஓ } \\
\text { ㅇ }\end{array}$ & $\begin{array}{c}15^{\circ} 94^{\prime} 284 " \mathrm{~S} \\
047^{\circ} 61^{\prime} 886^{\prime \prime} \mathrm{W}\end{array}$ & $\begin{array}{l}\text { Graciano- } \\
\text { Ribeiro et } \\
\quad \text { al. }\end{array}$ & 419 \\
\hline $\begin{array}{c}\text { Guadua } \\
\text { chacoensis } \\
\text { (Rojas) Londoño } \\
\text { \& P.M. Peterson }\end{array}$ & $\begin{array}{l}\text { Senador } \\
\text { Canedo - } \\
\text { GO }\end{array}$ & $\frac{n}{\frac{n}{2}}$ & $\begin{array}{r}16^{\circ} 72^{\prime} 087^{\prime \prime S} \\
049^{\circ} 13^{\prime} 259^{\prime \prime} \mathrm{W}\end{array}$ & $\begin{array}{l}\text { Graciano- } \\
\text { Ribeiro et } \\
\quad \text { al. }\end{array}$ & 399 \\
\hline $\begin{array}{l}\text { Guadua magna } \\
\text { Londoño \&Filg. }\end{array}$ & $\begin{array}{l}\text { Itaguari - } \\
\text { GO }\end{array}$ & 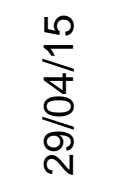 & $\begin{array}{c}15^{\circ} 56^{\prime} 482 \text { "S } \\
049^{\circ} 35^{\prime} 656^{\prime \prime} \mathrm{W}\end{array}$ & $\begin{array}{l}\text { Graciano- } \\
\text { Ribeiro et } \\
\quad \text { al. }\end{array}$ & 398 \\
\hline $\begin{array}{c}\text { Guadua } \\
\text { paniculataMunro }\end{array}$ & $\begin{array}{c}\text { Cavalcante - } \\
\text { GO }\end{array}$ & $\begin{array}{l}\frac{n}{\infty} \\
\frac{n}{8} \\
0\end{array}$ & $\begin{array}{c}13^{\circ} 28^{\prime} 74.3^{\prime \prime S} \\
047^{\circ} 57^{\prime} 71.7^{\prime \prime W}\end{array}$ & $\begin{array}{l}\text { Graciano- } \\
\text { Ribeiro et } \\
\quad \text { al. }\end{array}$ & 405 \\
\hline $\begin{array}{c}\text { Guadua refracta } \\
\text { Munro }\end{array}$ & $\begin{array}{l}\text { BR } 020 \text { Km } \\
\quad 44 \\
\text { Brasília - DF }\end{array}$ & $\begin{array}{l}\stackrel{n}{\infty} \\
\stackrel{\infty}{\infty} \\
\stackrel{\rho}{\rho}\end{array}$ & $\begin{array}{c}15^{\circ} 22 ' 247^{\prime \prime S} \\
047^{\circ} 06^{\prime} 169 " W\end{array}$ & $\begin{array}{l}\text { Graciano- } \\
\text { Ribeiro et } \\
\quad \text { al. }\end{array}$ & 416 \\
\hline Guadua sp. 01 & $\begin{array}{c}\text { Estrada } \\
\text { para } \\
\text { Curvelândia } \\
\text { - MT }\end{array}$ & 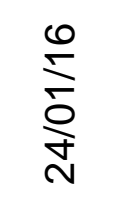 & $\begin{array}{c}15^{\circ} 34^{\prime} 055^{\prime \prime} \mathrm{S} \\
057^{\circ} 56^{\prime} 592^{\prime \prime} \mathrm{W}\end{array}$ & $\begin{array}{l}\text { Graciano- } \\
\text { Ribeiro et } \\
\quad \text { al. }\end{array}$ & 425 \\
\hline Guadua sp. 02 & $\begin{array}{c}\text { Figueirópolis } \\
\text { - MT }\end{array}$ & $\frac{0}{\frac{0}{\infty}}$ & $\begin{array}{c}15^{\circ} 24^{\prime} 519 " \mathrm{~S} \\
058^{\circ} 37^{\prime} 529^{\prime \prime} \mathrm{W}\end{array}$ & $\begin{array}{l}\text { Graciano- } \\
\text { Ribeiro et } \\
\quad \text { al. }\end{array}$ & 429 \\
\hline Guadua sp. 03 & $\begin{array}{l}\text { Goiânia - } \\
\text { GO }\end{array}$ & $\begin{array}{l}\frac{10}{\hbar} \\
\stackrel{0}{0} \\
0\end{array}$ & - & $\begin{array}{l}\text { Graciano- } \\
\text { Ribeiro et } \\
\quad \text { al. }\end{array}$ & 400 \\
\hline $\begin{array}{l}\text { Guadua virgata } \\
\text { (Trin.) Rupr. }\end{array}$ & Arinos - MG. & 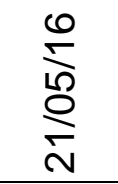 & $\begin{array}{c}15^{\circ} 53 \text { '096"S } \\
046^{\circ} 20^{\prime} 737^{\prime \prime W}\end{array}$ & $\begin{array}{l}\text { Cunha- } \\
\text { Santana } \\
\text { et al. }\end{array}$ & 435 \\
\hline
\end{tabular}




\section{RESULTADOS}

\section{Lâmina foliar}

Do tipo aberta, com nervura central proeminente na face abaxial, formato plano-convexo. A lâmina é reta da região próxima a nervura central até o bordo $A$, e ondulada próxima ao bordo B (fig. 1-4).

\section{Epiderme}

Uniestratificada e recoberta por cutícula espessa em G. cf. refracta (fig.), G. paniculata, G. sp. 01 e G. virgata, a densamente espessa em ambas as faces em G. aff magna, G. chacoensis, G. magna, G. refracta, G. sp. 02 e G. sp. 03. As células epidérmicas comuns $(\mathrm{Cec})$ são arredondadas, com paredes periclinais externas e internas espessas, e possuem tamanhos irregulares em ambas as faces em todas as espécies (fig. 1).

Ocorrem papilas em ambas as faces da superfície, observadas em maior quantidade na face abaxial das populações. Exceto em $G$. cf. magna, $G$. magna, e G. virgata.

As células buliformes estão presentes nas zonas intercostais (entre os feixes vasculares) da superfície adaxial e destacam-se pela área que ocupam no mesofilo - acima de 50\%: G. cf refracta, G. magna, G. sp. 02, G. sp. 03 e até $50 \%$ nas demais. Possuem formato leque com a célula central maior e em forma de gota (fig. 1), variando em 3-5 células na ala até o bordo $A$, e de 3-11 na ala até o bordo $B$ em todas as espécies. Estão localizadas geralmente na mesma linha das $\mathrm{Cec}$ podendo às vezes ser observadas acima destas.

Os estômatos são nivelados em relação às Cec. Localizam-se na região intercostal em ambas as faces, tendo maior concentração na face abaxial, o que caracteriza a folha como anfihipoestomática. Apresentam cavidade subestomática em todas as espécies (fig. 1).

\section{Mesofilo}

O mesofilo é homogêneo, formado por parênquima clorofiliano constituído de células invaginantes. A primeira camada de células mais próximas à face adaxial é composta por células quadradas ou alongadas, com invaginações estendidas até quase a parede oposta da célula. No restante do 
mesofilo ocorrem células retangulares a arredondadas com invaginações mais curtas (fig. 1-4).

Células fusoides de formato elíptico estão presentes em G. cf. magna, G. cf. refracta, G. magna, G. refracta, G. sp. 01, G. sp. 03, e G. virgata; são raras em G. sp. 02, e ausentes em G. chacoensis e G. paniculata. Nas espécies em que não foram observadas células fusoides nota-se uma fileira de células invaginantes retangulares na mesma posição em que nas outras encontramos as fusoides, no entanto, diferenciam-se destas por serem mais largas e alongadas (fig. 1).

\section{Feixes vasculares}

Os feixes vasculares na ala são feixes de $1^{\text {a }}$ e $3^{\circ}$ ordens, do tipo colateral, equidistantes ou mais próximos da face abaxial em todas as espécies. Os feixes de $1^{\underline{a}}$ ordem apresentam forma circular ou oval e são constituídos geralmente por 2 elementos de vaso no metaxilema (fig. 1).

Apresentam duas bainhas, uma externa parenquimática, incompleta nos feixes de $1^{\text {a }}$ ordem e completa nos feixes de $3^{\underline{a}}$ ordem, com quantidade variável de células; e a interna esclerenquimática (fig. 1). As extensões são esclerenquimáticas e estão presentes em todos os feixes, voltadas para ambas as faces da epiderme, sendo de formato cordão voltada para a adaxial e de formato retangular ou arqueado seguindo o contorno do feixe voltados para a abaxial nos feixes de $1^{\underline{a}}$ ordem e podem ter formato cordão voltado para a face adaxial e retangular ou quadrada voltadas para a face abaxial nos feixes de $3^{\text {a }}$ ordem.

Os feixes de $3^{\underline{a}}$ ordem possuem forma circular, ovais a elípticos. As espécies possuem cerca de 3-8 feixes vasculares de $3^{\text {a }}$ ordem consecutivos entre dois de $1^{\underline{a}}$ ordem. A distância intervenal difere: cerca de 3 a 5 células em G. cf. magna e G. magna; 4 a 6 em G. sp. 02; 5 em G. cf. refracta e $G$. paniculata; 5 a 8 em G. refracta, G. sp. 01 e G. sp. 03; e 6 a 8 em G. virgata e G. chacoensis (fig. 1). 


\section{Bordos}

Neste estudo foram considerados como bordo a região a partir do último feixe vascular, sendo este de $1^{\underline{a}}$ ou $3^{\underline{a}}$ ordem. Todas as espécies possuem bordos diferentes, o que se desenvolve primeiro é agudo, aqui referido como bordo $A$, e outro arredondado, que se desenvolve depois, referido como bordo B. Possuem cutícula densamente espessa, células epidérmicas comuns, células silicificadas, estômatos, papilas, parênquima clorofiliano formado por células invaginantes semelhantes às da ala (fig. 3 e 4).

Bordo A: Possuem extremidade aguda com estreitamento lignificado geralmente reto, ou voltado para a superfície adaxial (fig. 2). O feixe vascular terminal é de $1^{\underline{a}}$ ordem em $G$. cf magna, G. chacoensis, G. paniculata, $G$. refracta e G. sp 01. E de 3aㅡㄹ om G. cf refracta, G. magna, G. sp 02, G. sp 03 e G. virgata. Cavidade de macrotricoma.

Bordo B: Extremidade arredondada a oval ou triangular em G. magna, com fibras na porção terminal, sendo o feixe vascular terminal de $3^{\text {a }}$ ordem em G. cf. refracta, G. chacoensis e G. magna, e de 1a ordem nas demais populações (fig. 3).

\section{Nervura central}

A nervura central nas espécies é proeminente com formato planoconvexo. Possui $\mathrm{Cec}$, estômatos, células silicificadas, cutícula espessa a densamente espessa em ambas as faces. É simples, com apenas um feixe vascular, apenas em G. paniculata; e complexa, com mais de um feixe vascular, nas demais estudadas (fig. 4).

O sistema vascular consiste de feixes vasculares colaterais de $1^{\underline{a}}$ e de $2^{\underline{a}}$ ordem, sendo que em G. sp. 03além destes, ainda há um pequeno feixe de $3^{a}$ ordem (Fig. 4). Os feixes vasculares de $2^{\underline{a}}$ ordem são elípticos, não possuem bainha parenquimática, e estão envoltos pelas fibras esclerenquimáticas. Os de $1^{\text {a }}$ ordem, nas espécies em que a nervura central é complexa, são de formato arredondado, e não possuem bainha parenquimática. Podem apresentar células parenquimáticas hexagonais a isodiamétricas na região central da 
nervura em G. cf. magna, G. cf. refracta, G. chacoensis, G. magna, G. refracta, e G. sp 03).

Na espécie em que a nervura central é simples, o feixe de $1^{\text {a }}$ ordem possui duas bainhas, parenquimática e esclerenquimática, sendo a parenquimática interrompida (fig. 4.).

\section{DISCUSSÃO}

As populações apresentam cutícula espessa, epiderme uniestratificada e os mesmos tipos celulares já citados para Bambusoideae: presença de tricomas, células silicificadas frequentes com formatos variados, papilas, mesofilo homogêneo formado por células invaginantes e feixes vasculares com duas bainhas: uma parenquimática e outra esclerenquimática, revelando um padrão na lâmina foliar (ELLIS, 1976,1979; RENVOIZE, 1987; JUDZIEWCZ et al., 1999; VIEIRA et al., 2002;GRACIANO-RIBEIRO et al., 2006; YANG et al., 2008; MARQUEZ et al., 2011; VIANA et al., 2013a; 2013b; GUERREIRO et al., 2013; LEANDRO et al., 2016; PANIZZO et al., 2016).

O espessamento das paredes das células epidérmicas é sustentado na literatura como frequente em plantas de ambientes secos, visto que tal caráter está presente em quase todas as espécies xeromórficas estudadas (FAHN \& CUTLER, 1992).

Células epidérmicas comuns com paredes periclinais externas espessas e anticlinais delgadas, cutícula espessa a densamente espessa, papilas e tricomas abundantes, foram observadas nas espécies, confirmando os trabalhos de Montiel et al (2006a), Montiel et al. (2006b), Montiel et al (2006c), Montiel et al (2006d), Montiel et al (2006e), Marquéz (2011) e Panizzo et al (2016) que também estudaram a anatomia de espécies Guadua.

Segundo Fahn e Cutler (1992) o espessamento da cutícula e das paredes das células epidérmicas é frequente em plantas de ambientes secos e é determinado pelo grau de exposição ao sol. Algumas espécies deste estudo foram coletadas em área de mata ciliar, com disponibilidade de água e por vezes protegidas por outras plantas; e outra parte em beira de estrada, ficando 
assim mais expostas ao sol. Com isso, a espessura da parede e densidade da cutícula nas células epidérmicas comuns talvez possa ser determinada por outros fatores além destes.

Algumas espécies deste estudo foram coletadas em área de mata ciliar, com disponibilidade de água e por vezes protegidas por outras plantas; e outra parte em beira de estrada, ficando assim mais expostas ao sol. Sendo assim a espessura da parede e densidade da cutícula nas células epidérmicas comuns talvez possa ser determinada por outros fatores além deste.

Nas espécies estudadas, células buliformes destacam-se pela quantidade que ocupam no mesofilo, $50 \%$ ou mais, e também pela presença de papilas, podendo ser considerada uma característica do gênero.

Os complexos estomáticos se encontram no mesmo nível das demais células epidérmicas em ambas as faces ou localizam-se pouco abaixo na superfície adaxial e possuem uma cavidade subestomática discreta. Além disso, são encobertos por papilas na face adaxial e apenas envoltos na abaxial. Segundo Metcalfe (1960) e Dickison (2000), essas características são encontradas em gramíneas que habitam lugares de alta intensidade luminosa e/ou podem se desenvolver como respostas às condições ambientais afim de evitar a perda de água por transpiração. Nas espécies coletada em ambientes com alta intensidade luminosa e secos provavelmente esses caracteres estejam ligados à perda de água.

O mesofilo composto basicamente por células invaginantes é um caráter único compartilhado pelos membros da subfamília Bambusoideae (ZHANG \& CLARK, 2000).

As células fusoides, citadas por Ellis (1976), Soderstrom e Ellis (1987) e Londoño e Clark (2004) como característica da subfamília Bambusoideae, muito raras de se observar em outras subfamílias, estão ausentes em $G$. paniculata e G. chacoensis. March e Clark (2011) também citaram a ausência de células fusoides nas espécies Yushania niitakayamensis (Hayata) Keng f e Phyllostachys áurea Carrière ex Rivière \& C. Rivière. Clark (1991) e March e Clark (2011) inferem que a ocorrência de células fusoides pode estar 
relacionada com variações anatômicas entre folhas de sol e sombra, e a diferentes pressões adaptativas.

Vieira et al. (2002) e Wang et al., (2016) inferiram que as células fusoides estavam relacionadas ao armazenamento e transporte de água e regulagem o equilíbrio hídrico das folhas devido a sua posição, próximas aos feixes vasculares. Por esta razão March e Clark (2011) afirmaram que a presença de células fusóides em alguns bambus lignificados pode ser facultativa de acordo com o tamanho e a forma das folhas de sol ou sombra até no mesmo indivíduo. A forma e o tamanho das folhas dos Bambusoideae podem estar relacionadas à presença de células fusóides, que mantêm a conformidade da folha independentemente de um eventual estresse por estiagem (VEGA et al., 2016).

Vega et al. (2016) realizaram um estudo de ontogenia das células fusoides em espécies Guadua e de acordo com observações anatômicas de seções transversais, as células fusóides, referidas por vários autores em descrições anatômicas, são na verdade os espaços intercelulares de ar conspícuos formados por células colapsadas (raramente não colapsadas). Verificaram também que pode ocorrer transdiferenciação, quando células de clorênquima se transformam em células fusoides. Sustentando a hipótese de homologia entre esses dois tipos de celulares, proposta por March e Clark (2011).

Nota-se que nos feixes vasculares de $1^{\underline{a}}$ e $3^{\underline{a}}$ ordens ao longo da ala existe uma bainha esclerenquimática interna à parenquimática que segundo Brandis (1907) falta em muitas gramíneas, mas está presente em Bambuseae. A distribuição dos feixes vasculares pode variar de espécie para espécie dentro do mesmo gênero, sendo assim, relevantes na delimitação de táxons (METCALFE, 1956; ELLIS, 1976).

O sistema vascular complexo na nervura central da lâmina foliar é considerada uma característica típica de Guaduinae (SODERSTROM \& ELLIS 1986), mas não confere uma distinção consistente entre subtribos, uma vez que Viana e al. (2013) cita a presença de nervura central complexa como 
característica de Chusqueinae, e nervura central simples característica de Arthrostylidiinae. Ambas características também observadas neste estudo.

Os feixes vasculares da nervura central estão dispostos entre as fibras esclerenquimáticas, Brandis (1907) citou essa característica para a nervura central de alguns bambus afirmando que as fibras esclerenquimáticas se uniram, e os feixes vasculares da nervura central estão encaixados nesta massa de fibras. 


\section{CONCLUSÃO}

Os estudos revelaram novidades sobre a organização anatômica das espécies atualmente aceitas para Guadua. Considerando a utilização dos caracteres de anatomia foliar para a diferenciação das espécies, a ausência de células fusoides e nervura central simples diferenciam anatomicamente $G$. paniculata; e a nervura central complexa com ausência de células fusoides diferencia G. chacoensis. As lâminas foliares das populações Guadua estudadas apresentam características anatômicas em comum tais como: mesofilo homogêneo, feixes vasculares colaterais de $1^{\underline{a}}$ e $3^{\text {a }}$ ordens ao longo da ala foliar, bordos diferentes entre sí, estômatos em ambas as faces da epiderme, células silicificadas abundantes e de formatos variados, presença de macrotricomas, ganchos e espinhos. Tais caracteres, que não apresentaram grandes variações entre as espécies, merecem destaque pelo fato de poderem ser úteis para caracterização do gênero como um todo.

Como características diferenciais temos a ausência de células fusoides em $G$. paniculata e $G$. refracta, nervura central simples em $G$. paniculata, ausência de papilas em $G$. magna, $G$. cf. magna e $G$. virgata, bem como a ausência de microtricomas em $G$. magna e $G$. cf. magna.

Características como a presença ou ausência de papilas e células fusoides podem estar relacionadas às condições ambientais as quais a planta está exposta. 


\section{REFERÊNCIAS BIBLIOGRÁFICAS}

BRANDIS, S.D. Remarks on the Struture of Bamboo Leaves. Transactions of the Linnean Society of London. v.2(7). pp. 69-92. 1907.

CARVALHO, A.L. Ciclo de vida de populações de bambu (Guadua spp.) no tempo e no espaço, no Sudoeste da Amazônia. Dissertação. Instituto Nacional de Pesquisas da Amazônia - INPA. Programa de Pós-Graduação em Ciências de Floresta Tropicais - CFT. 2009.

CLARK, L.G. The function of fusoid cells in bamboos: an hypothesis. American Journal of Botany. v.78(22). (Abstracts). 1991.

DICKISON, W.C. Ecological anatomy. In Integrative Plant Anatomy., ed. DICKISON, W.C. USA: Academic Press. Pp 295-338. 2000.

ELLIS, R.P. A procedure for standardizing comparative leaf anatomy in the Poaceae. I. The leaf-blade as viewed in transverse section. Bothalia. v.12. pp. 65-109. 1976.

ELLIS, R.P. A procedure for standardizing comparative leaf anatomy in the Poaceae II: the epidermis as seen in surface view. Bothalia. v.12. pp. 641-671. 1979.

FAHN, A.; CUTLER, D. Xerophytes. Gebruder Borntraeger. Berlin. 1992.

FISHER, A.E.; TRIPLETT, J.K.; HO, C.S.; SCHILLER, A.D.; OLTROGGE, K.A.; SCHRODER, E.S.; KELCHNER, S.A.; CLARK, L.G. Paraphyly in the bamboo subtribe Chusqueinae (Poaceae: Bambusoideae) and a revised infrageneric classification for Chusquea. Systematic Botany. v.34. pp. 673-683. 2009.

GRACIANO-RIBEIRO, D.; FILGUEIRAS, T. D; SANTOS-GONÇALVES, A. P. Roteiro Mínimo para Estudo Anatômico dos Bambus (Poaceae: Bambusoideae). In: Anais do I Seminário Nacional do Bambu. Brasília-DF, set. 2006.

GUERREIRO, C.; RÚGOLO DE AGRASAR, Z. E.; RODRIÍGUEZ, F. M. A contribuition to the identification of vegetative Andean woody bamboos in southernmost America using leaf anatomy. The Journal of the Torrey Botanical Society. v.140(3). pp.259-268. 2013.

JENSEN, W. A. Botanical Histochemistry: principles and practices. São Francisco: W.H. Freeman, 1962.

JUDZIEWICZ, E. J.; CLARK, L. G.; LONDOÑO, X. \& STERN, M. J. American bamboos. Washignton, D. C., Smithsonian Institution Press, 392 pp, 1999.

JUDZIEWICZ, E. J.; CLARK. L. G. Classification and biogeography of New World grasses: Anomochlooideae, Pharoideae, Ehrhartoideae, and Bambusoideae. Aliso: A Journal of Systematic and Evolutionary Botany. v. 23. pp. 303-314. 2007. 
KRAUS, J. E.; ARDUIN, M. Manual Básico de Métodos em Morfologia Vegetal. Seropédica: Edur, 1997.

KRAUS, J.E.; ARDUIN, M. Manual Básico de Métodos em Morfologia Vegetal. Seropédica: Edur, 1997.

LEANDRO, T.D.; SHIRASUNA, R.T.; FILGUEIRAS, T.S.; SCATENA, V.L. The utility of Bambusoideae (Poaceae, Poales) leaf blade anatomy for identification and systematics. Brazilian Journal of Biology. 2016.

LONDOÑO, X. Two new Guadua species for Peru (Poaceae: Bambusoideae: Bambuseae: Guaduinae).Journal of the Botanical Research. Inst. Texas v.7. pp. 145-153. 2013.

LONDOÑO, X; CLARK, L.G. A Revision of the Brazilian Bamboo Genus Eremocaulon (Poaceae: Bambuseae: Guaduinae). Systematic Botany. v.27. pp. 703-721. 2002.

LONDOÑO, X.; CLARK, L.G. Distribucion, Morfologia, Taxonomia, Anatomia, Silvicultura y Usos de los Bambues del Nuevo Mundo. In. III Congreso Colombiano de Botanica. Novembro. 2004.

LONDOÑO, X.; PETERSON, P.M. Guadua chacoensis (Poaceae: Bambuseae), Its Taxonomic Identity, Morphology, and Affinities. Novon. vol. 2(1). pp. 414.1992.

MARCH, R.H.; CLARK, L.G. Sun-shade variation in bamboo (Poaceae: Bambusoideae) leaves. Royal Botanic Gardensand Domais Trust. v.13. pp. 93-104. 2011.

MÁRQUEZ, L.; GARCÍA, M.; DOUGLAS, M. Anatomía foliar de Guadua angustifolia KUNTH, G. amplexifolia PRESL. Y Elytrostachys typica MCCLURE (POACEAE, BAMBUSOIDEAE). Ernstia. v. 21. pp. 91-109. 2011.

METCALFE, C. R. Anatomy of the Monocotyledons. I. Gramineae. Oxford University Press. Amen House. Londres, 1960.

MONTIEL, M.; JIMÉNEZ, V.M.; GUEVARA. E. Ultraestructura del bambú Guadua angustifolia var. bicolor (Poaceae: Bambusoideae), presente en Costa Rica. Revista Biologia Tropical. v. 54. p. 13-19, 2006a.

MONTIEL, M.; JIMÉNEZ, V.M.; GUEVARA. E. Caracterización anatómica ultraestructural de tres variaciones de la especie de bambú Guadua angustifolia, "Atlántica", "Sur" y "Cebolla", en Costa Rica. Revista Biologia Tropical. v. 54. p. 1-12, 2006b.

MONTIEL, M.; GUEVARA, E.; JIMÉNEZ, V.M. Ultraestructura del bambú Guadua macclurei (Poaceae: Bambusoideae) de Costa Rica. Revista Biologia Tropical. v. 54. p. 35-42, 2006c.

MONTIEL, M. GUEVARA, E.; JIMÉNEZ, V.M. Ultraestructura del bambú Guadua paniculata (Poaceae: Bambusoideae) de Costa Rica. Revista Biologia Tropical. V. 54. p. 29-34, 2006d. 
MONTIEL, M.; JIMÉNEZ, V.M.; GUEVARA. E. Ultraestructura del bambú Guadua amplexifolia (Poaceaea: Bambusoideae) presente en Costa Rica. Revista Biologia Tropical. v. 54. p. 21-28, 2006 e.

PAIVA, J.G.A.; FRANK-DE-CARVALHO, S.M; MAGALHÃES, M.P.; GRACIANO-RIBEIRO, D. Verniz vitral incolor 500®: uma alternativa de meio de montagem economicamente viável. Acta Botânica Brasílica. v.20. pp. 257264. 2006.

PANIZZO, C.C.; FERNANDEZ, P.V. COLOMBATTO, D. CIANCIAB, M.; VEGA, A.S. Anatomy, nutritional value, and cell wall chemical analysis of foliage leaves in Guadua chacoensis (Poaceae: Bambusoideae: Bambuseae), a promising source of forage. 2016.

RENVOIZE, S.A. A survey of leaf blade anatomy in grasses X. Bambuseae. Kew Bulletin.v.42. pp. 201-207. 1987.

RUIZ-SANCHEZ, E.; SOSA, V.; MEJÍA-SAULES, M.T. Phylogenetics of Otatea inferred from morphology and chloroplast DNA sequence data and recircumscription of Guaduinae (Poaceae: Bambusoideae). Systematic Botany. v.33. pp. 277-283. 2008.

RUIZ-SANCHEZ, E.; SOSA, V.; MEJÍA-SAULÉS, M.T.; LONDOÑO, X.; CLARK, L.G. A taxonomic revision of Otatea (Poaceae: Bambusoideae: Bambuseae) including four new species. Systematic Botany. v. 36. Pp. 314-336. 2011.

SODERSTROM, T. R; ELLIS, R. P. The position of bamboo genera and allies in a system of grass classification. In: Grass Systematics And Evolution, eds. T.R. Doderstrom, K.W. Hilu, C.S. Campbell, and M.E. Barkworth. Washington DC: Smithsonian Institution Press. Pp. 225-238. 1987.

SODERSTROM, T.R.; LONDOÑO, X. Two new genera of Brazilian bamboos related to Guadua (Poaceae: Bambusoideae: Bambusea). American Journal of Botany. v.74. pp. 27-39. 1987

VEGA, A.S.; CASTRO, M.A.; GUERREIRO, C. Ontogeny of fusoid cells in Guadua species (Poaceae, Bambusoideae, Bambuseae): evidence for transdifferentiation and possible functions. Flora Journal. v.222. pp. 13-19. 2016.

VIANA, P.L.; FILGUEIRAS, T.S.; CLARK, L.G. Cambajuva (Poaceae: Bambusoideae: Bambuseae: Arthrostylidiinae), a new woody bamboo genus from Southern Brazil. Systematic Botany. v. 38. Pp. 97-103. 2013.

VIANA, P.L.; FILGUEIRAS, T.S.; GRACIANO-RIBEIRO, D. A new woody bamboo (Poaceae: Bambusoideae) from Central Brazil. Novon. v.22. pp.371376. 2013b.

VIEIRA, R. C.; GOMES, V. R. C.; SARAHYBA, D. M. S.; ARRUDA, R. C. O. Leaf anatomy of three herbaceous bamboo species. Brazilian Journal of Biology. v.62. pp. 907-922. 2002. 
WANG, S.; ZHANG, H.; LIN, S.; HSE, C.; DING, Y. Anatomical characteristics of fusoid cells and vascular bundles in Fargesia yunnanensis leaves. Northeast Forestry University and Springer-Verlag Berlin Heidelberg. 2016.

YANG, H. Q.; WANG, H.; LI, D. H. Comparative morphology of rhe foliage leaf epidermis, with emphasis on papillae characters, in key taxa of woody bamboos of the Asian tropics (Poaceae: Bambusoideae). Botanical Journal of the Linnean Society. v.156. pp. 411-423. 2008.

ZHANG, W. \& CLARK, L.G. Phylogeny and classification of the Bambusoideae (Poaceae). In: S.W.L. Jacobs \& J. Everert (eds.). Grass Systematics and Evolution.Melbourne, CSIRO, 2000. 


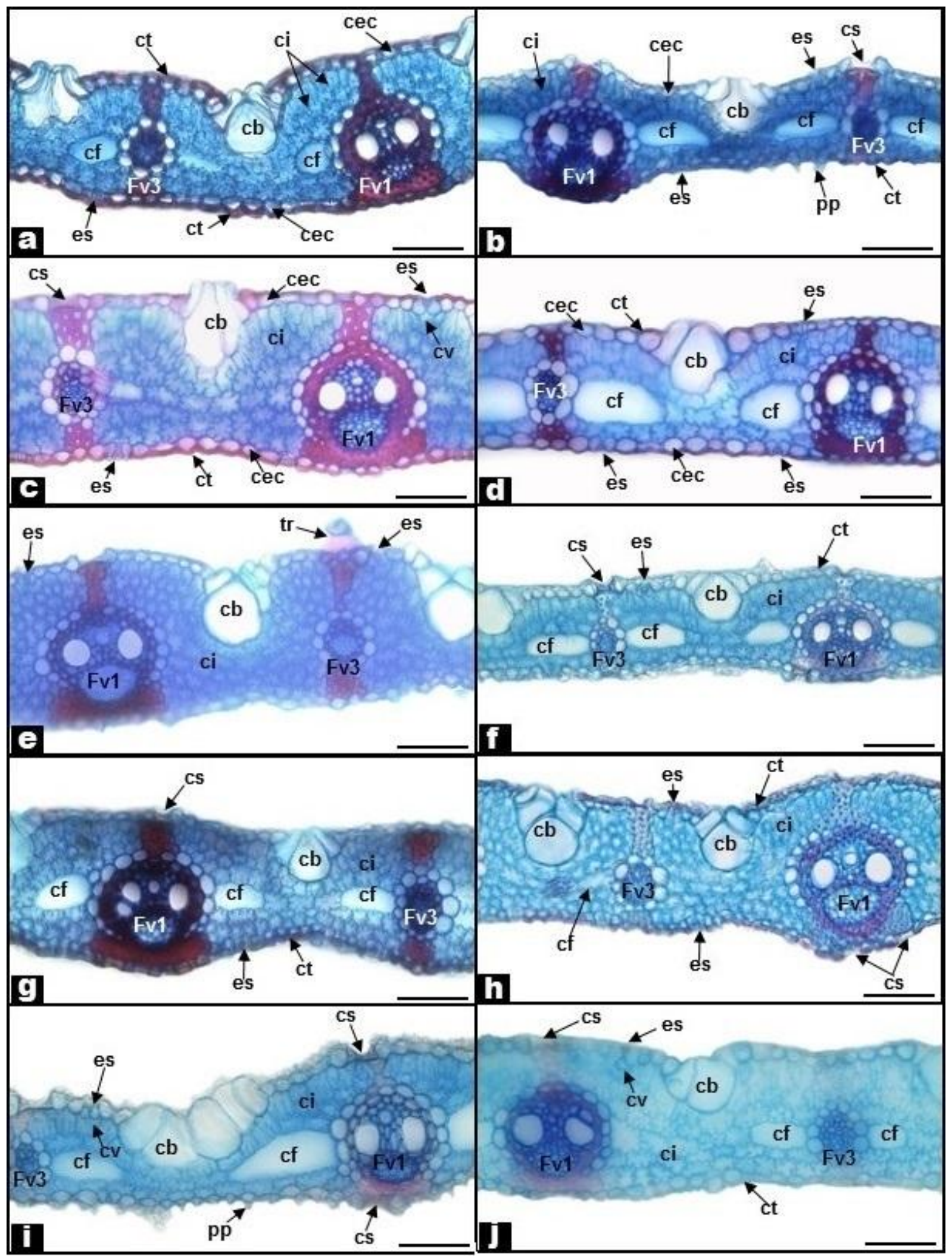

Figura 01: Secção transversal da lâmina foliar de espécies Guadua evidenciando o mesofilo homogêneo, formado por células invaginantes. A: G. cf magna; B: G. cf refracta; C: G. chacoensis; D: G. magna; E: G. paniculata; F: G. refracta; G: G. sp 01; H: G. sp 02; I: G. sp 03; J: G. virgata. cb: células buliformes; ct: cutícula; es: estômato; cf: célula fusoide; cec: células epidérmicas comuns; ci: células invaginantes; cs: célula silicificada; $\mathbf{c v}$ : cavidade subestomática; fv1: feixe vascular de $1^{\text {a }}$ ordem; fv3: feixe vascular de $3^{\mathrm{a}}$ ordem; pp: papilas. Barra $=100 \mu \mathrm{m}$. 


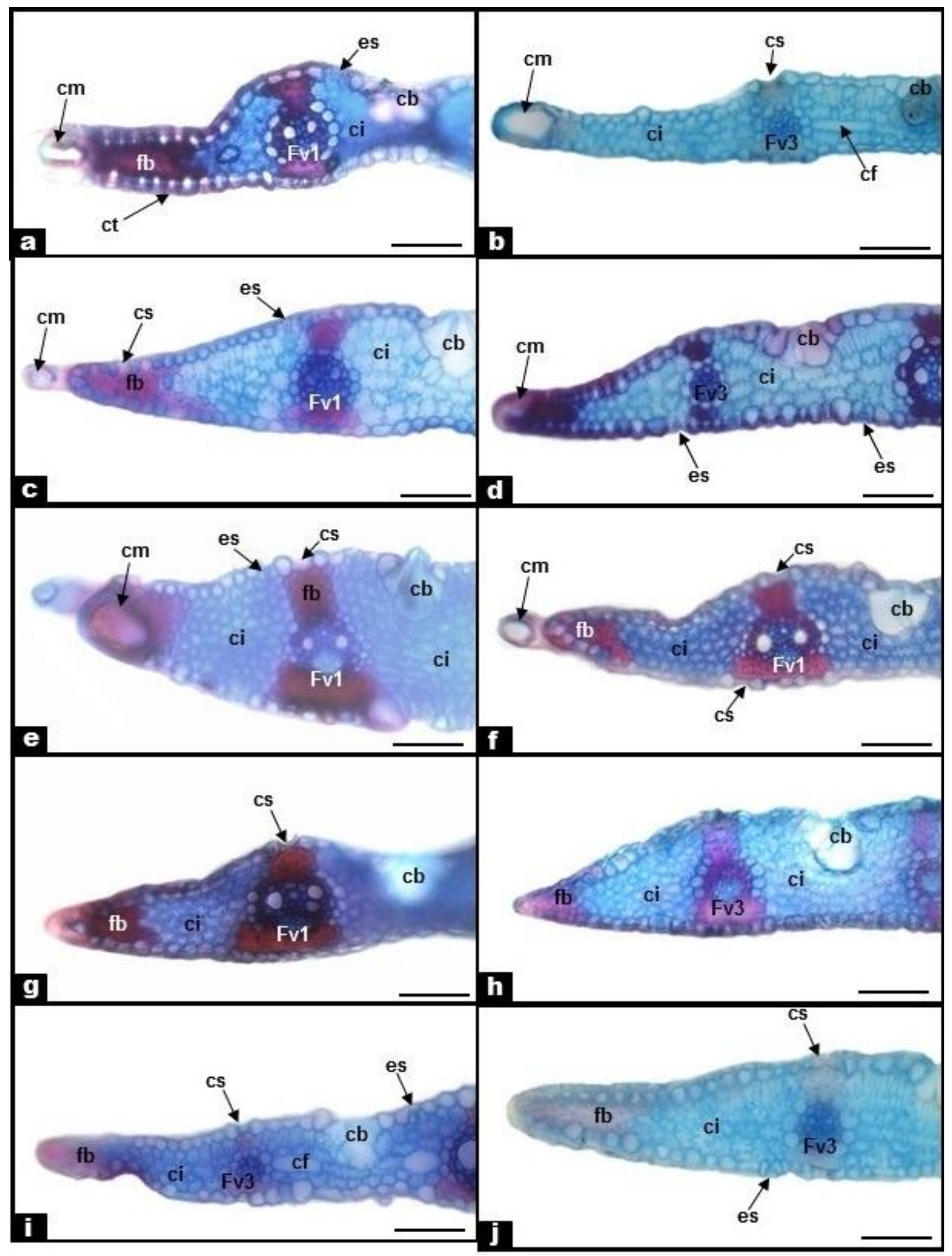

Figura 02: Secção transversal da lâmina foliar de espécies Guadua evidenciando detalhes do bordo A. A: G. cf magna; B: G. cf refracta; C: G. chacoensis; D: G. magna; E: G. paniculata; F: G. refracta; G: G. sp 01; H: G. sp 02; I: G. sp 03; J: G. virgata. cb: células buliformes; ct: cutícula; es: estômato; fb: fbras; cf: célula fusoide; ci: células invaginantes; cs: célula silicificada; fv1: feixe vascular de $1^{\text {a }}$ ordem; fv3: feixe vascular de $3^{\mathrm{a}}$ ordem; $\mathbf{c m}$ : cavidade de macrotricoma. Barra $=100 \mu \mathrm{m}$. 


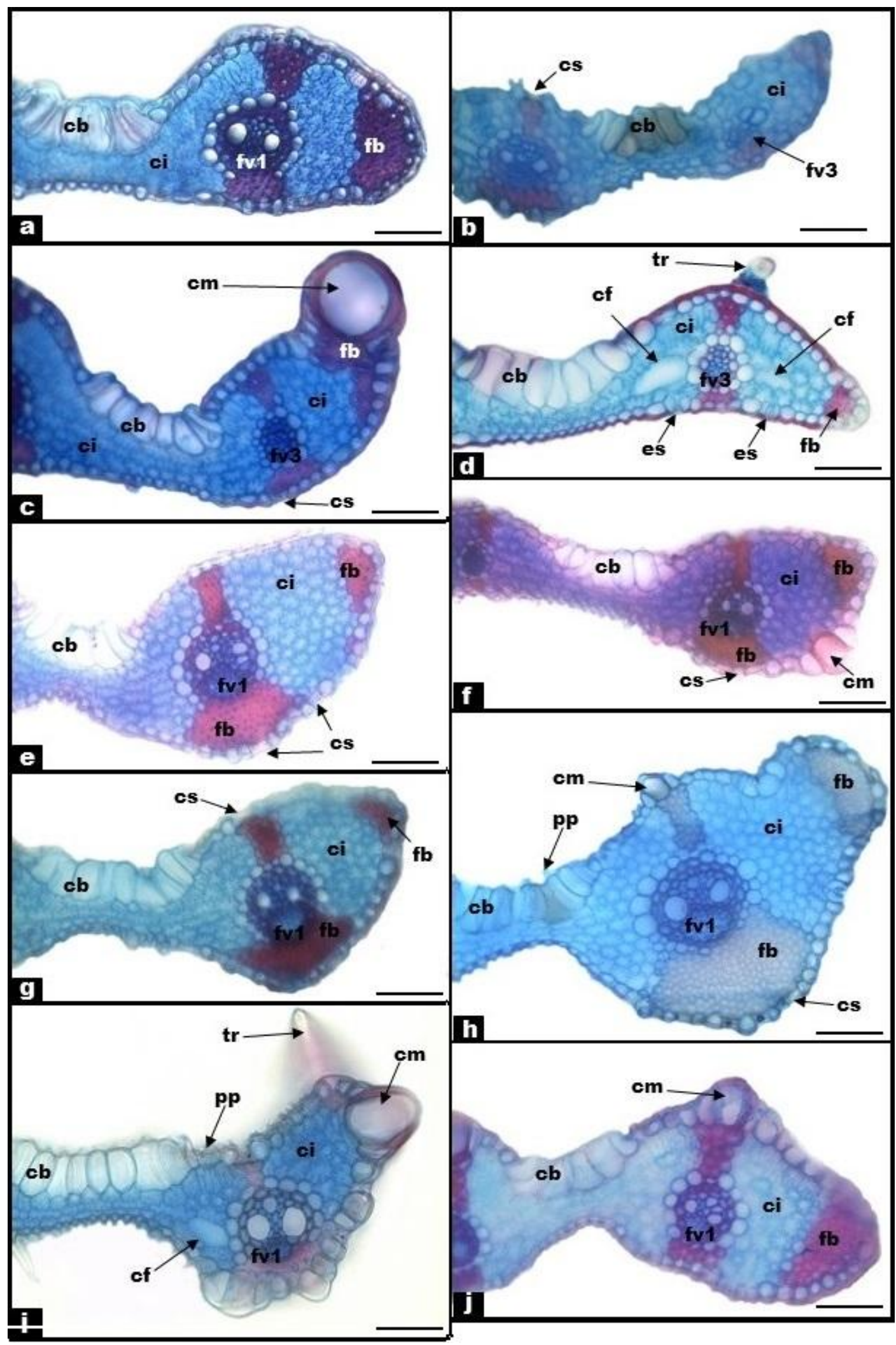

Figura 03: Secção transversal da lâmina foliar de espécies Guadua evidenciando detalhes do bordo B. A: G. cf magna; B: G. cf refracta; C: G. chacoensis; D: G. magna; E: G. paniculata; F: G. refracta; G: G. sp 01; H: G. sp 02; I: G. sp 03; J: G. virgata. cb: células buliformes; ct: cutícula; es: estômato; cf: célula fusoide; fb: fibras; ci: células invaginantes; cs: célula silicificada; fv1: feixe vascular de $1^{\mathrm{a}}$ ordem; fv3: feixe vascular de $3^{\mathrm{a}}$ ordem; $\mathbf{c m}$ : cavidade de macrotricoma pp: papilas; tr: tricoma tector. Barra $=100 \mu \mathrm{m}$. 


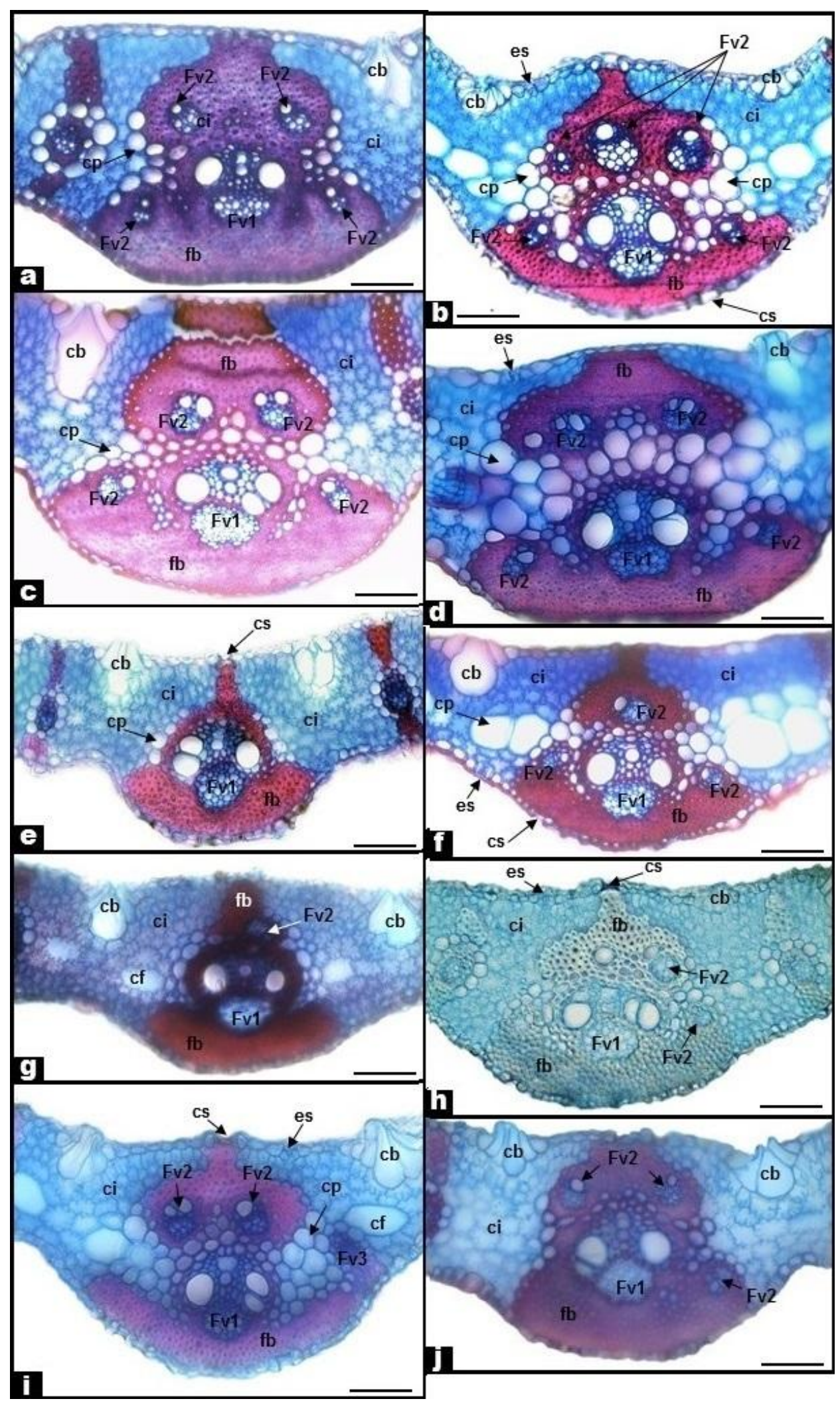

Figura 04: Secção transversal da lâmina foliar de espécies Guadua evidenciando detalhes da nervura central. A: $G$. cf magna; B: $G$. cf refracta; C: G. chacoensis; D: G. magna; E: G. paniculata; F: G. refracta; G: G. sp 01; H: G. sp 02; I: G. sp 03; J: G. virgata. cb: células buliformes; ct: cutícula; es: estômato; cf: célula fusoide; $\mathbf{c e c}$ : células epidérmicas comuns; ci: células invaginantes; cs: célula silicificada; fv1: feixe vascular de 1를 ordem; fv2: feixe vascular de $2^{\mathrm{a}}$ ordem. Barra $=100 \mu \mathrm{m}$. 